\title{
Testing of Candidate Rigid Heatshield Materials at LHMEL for the Entry, Descent, and Landing Technology Development Project
}

\author{
Steven Sepka ${ }^{1}$ \\ ERC Incorporated, Huntsville, AL, 35805 \\ Robin A. Beck ${ }^{2}$ and Susan White ${ }^{3}$ \\ NASA-Ames Research Center, Moffett Field, CA, 94035
}

\begin{abstract}
To further the technologies required to land heavy ( $\sim 40$ metric ton) masses on Mars, material testing was done at the Wright-Patterson Air Force Base Laser Hardened Materials Laboratory (LHMEL) using a 10.6 micron $\mathrm{CO}_{2}$ laser operating with the test articles immersed in a nitrogen-gas environment at 1 atmosphere pressure. Test measurements included thermocouples for bond line temperatures, pyrometer readings of surface temperatures, mass loss, and char depth. Two laser exposures were applied. The first, which was given to all test models, was at $450 \mathrm{~W} / \mathrm{cm}^{2}$ for 60 seconds to simulate an aerocapture maneuver. The second laser exposure was at $115 \mathrm{~W} / \mathrm{cm}^{2}$ for 100 seconds to simulate a planetary entry. The second exposure was given to only one model of each tested material. The results described herein were part of a material screening testing program of vendor-supplied, proposed heat shield materials. This work was part of NASA's Entry Descent and Landing (EDL), Technology Development Project (TDP), Thermal Protection Systems (TPS) element, rigid materials development task. The goal of this EDL TDP TPS element was to develop low density, rigid material systems with an appreciable weight savings over the predicted requirements for PICA while improving its material response performance. In addition, new technologies, such as having PICA-like materials in honeycomb to avoid a gapped tile system or having materials with variable density through-the-thickness were studied. For these tests, seven different materials were tested: PICA (representing the baseline configuration), 3DQP, BPAFG, CC/CALCARB, LM-MonA, $P 28 / P 15$, and PIRAS-22. Results from the testing are summarized in this report. Findings from these tests were incorporated into the down-selection process for subsequent material development.
\end{abstract}

\footnotetext{
${ }^{1}$ Senior Research Scientist, NASA-Ames Research Center, Thermal Protection Materials \& Systems Branch (TSM) MS-234-1, Moffett Field, CA, 94035

${ }^{2}$ Aerospace Engineer, Entry Sytems and Vehicle Development Branch (TSS), MS-N229-1, Moffett Field CA, 94035.

${ }^{3}$ Research Engineer, Thermal Protection Materials and Systems Branch, Mail Stop 234-1.
} 


\title{
Testing of Candidate Rigid Heat Shield Materials at LHMEL for the Entry, Descent, and Landing Technology Development Project
}

\author{
Steven Sepka ${ }^{1}$ \\ ERC Incorporated, Huntsville, AL, 35805 \\ Matthew Gasch, ${ }^{2}$ Robin A. Beck, ${ }^{3}$ and Susan White ${ }^{4}$ \\ NASA Ames Research Center, Moffett Field, CA, 94035
}

\begin{abstract}
The material testing results described in this paper were part of a material development program of vendor-supplied, proposed heat shield materials. The goal of this program was to develop low density, rigid material systems with an appreciable weight savings over phenolic-impregnated carbon ablator (PICA) while improving material response performance. New technologies, such as PICA-like materials in honeycomb or materials with variable density through-the-thickness were tested. The material testing took place at the Wright-Patterson Air Force Base Laser Hardened Materials Laboratory (LHMEL) using a $\mathbf{1 0 . 6}$ micron $\mathrm{CO}_{2}$ laser operating with the test articles immersed in a nitrogen-gas environment at 1 atmosphere pressure. Test measurements included thermocouple readings of in-depth temperatures, pyrometer readings of surface temperatures, weight scale readings of mass loss, and sectioned-sample readings of char depth. Two laser exposures were applied. The first exposure was at an irradiance of $\mathbf{4 5 0}$ $\mathrm{W} / \mathrm{cm}^{2}$ for 50 or 60 seconds to simulate an aerocapture maneuver. The second laser exposure was at an irradiance of $115 \mathrm{~W} / \mathrm{cm}^{2}$ for 100 seconds to simulate a planetary entry. Results from Rounds 1 and 2 of these screening tests are summarized.
\end{abstract}

\section{Introduction}

\section{A. Background}

Most ablative heat shields are too large to be constructed from a single piece of material. For a multi-piece ablative heats shield, the standard approach to avoid windward-facing gaps is to bond together the various pieces. NASA used this gap bonding method for the Pioneer-Venus and Galileo entry probes, and more recently for Mars Science Laboratory ${ }^{1}$ (MSL) that will reach Mars in August 2012. Space-X also used bonding for the Dragon capsule that successfully

\footnotetext{
1 Senior Research Scientist, NASA-Ames Research Center, Thermal Protection Materials Branch (TSM) MS-N234-1, Moffett Field, CA, 94035

${ }^{2}$ Aerospace Engineer, Thermal Protection Materials Branch (TSM), MS-N234-1, Moffett Field CA, 94035.

3 Aerospace Engineer, Entry Sytems and Vehicle Development Branch (TSS), MS-N229-1, Moffett Field CA, 94035.

${ }^{4}$ Research Engineer, Thermal Protection Materials Branch, Mail Stop 234-1, Moffett Field CA, 94035. 
entered from Earth orbit in December 2010. Both MSL and Dragon use relatively large pieces of phenolic-impregnated carbon ablator $\left(\mathrm{PICA}^{2}\right)$ bonded together with room temperature vulcanizing silicone rubber (RTV-560). An alternative, labor-intensive approach is to cover the forebody structure with a filled honeycomb. This approach was used with Avcoat ablator for Apollo $^{3}$ and SLA-561V ablator for all NASA Mars missions prior to MSL. ${ }^{4}$ Both bonded and honeycomb heat shields may be described as monolithic.

There are some notable exceptions to the two methods of bonding and honeycomb. For example, the Stardust ${ }^{5}$ entry probe was sufficiently small such that the forebody heatshield could be manufactured as a single piece of shape-cast PICA. The small DS-2 probes were machined from near-net-shape tiles, and then impregnated with silicone. The Genesis probe used an external carbon shell with large structural attachments that penetrated through a porous carbon insulator.

For bonded and honeycomb heat shields, it is preferential to have the honeycomb or bond recede at an equal or only slightly faster rate than the acreage material(s). For aeroheating environments where the ablator recedes faster than the bond/honeycomb, protrusions can develop which may create flow disturbances ${ }^{6}$ and heating augmentation. This heating augmentation should be taken into account for sizing the material thickness.

For example, aerothermal environments severe enough for ablation can be found in direct planetary entry with entry high velocity and ballistic coefficients, or in an aerocapture maneuver to decelerate a spacecraft into orbit by using a planet's upper-atmosphere for drag. However, for the later stages of direct entry or for planetary entry after aerocapture, the aerothermal environment is usually mild enough to warrant the use of an insulator. By tailoring the density of TPS materials to have sufficient material for each phase of entry, significant mass savings ${ }^{7}$ can $^{-}$ be achieved. Recently, a series of arc-jet experiments ${ }^{8}$ at NASA Ames were conducted to study this effect. These tests had an ablator, PICA, stacked on top of an insulator, LI-900. Results from this study validated the "dual layer" concept.

An ablator can be considered to consist of three primary parts: a reinforcing material such as metallic honeycomb or ceramic matrix, fillers such as microballoons or cork, and a polymeric binder such as phenolic resin to act as an adhesive for all of the components. ${ }^{9}$ The current stateof-the-art for low-density ablators is PICA. In the past, low-density ablators such as this have been used for Earth and Martian planetary entry. One limitation of PICA is that it cannot be fabricated into very large pieces; therefore, a large heat shield may require abutment or bonding. Recent efforts, however, have been to place PICA into a metallic honeycomb. ${ }^{10}$ Additionally, although PICA is currently available as only a single density material, secondary impregnation techniques have been developed to densify the outer surface to a depth of approximately $2 \mathrm{~cm}$.

The results presented here were part of a material screening testing program of vendorsupplied, proposed heat shield materials. The goal was to develop materials with better ablative performance than PICA with appreciable weight savings. In particular, new designs using proprietary materials, varying density (i.e. functionally graded) through the material, and the use of honeycomb-based systems will be evaluated for thermal performance.

The usual approach in heat shield design is to determine the amount of heat shield material required to keep a bond line temperature below a desired value when the heat shield is exposed to an aerothermal heat pulse. For the current screening work, the problem was the inverse, i.e., if material thickness was chosen to keep areal density constant, how would the bond line temperature differ between materials. Other properties of interest included char depth (or percentage virgin material remaining), mass loss, and the general response of the material based 
on visual inspection. This work was part of NASA's Entry Descent and Landing (EDL), Technology Development Project (TDP), Thermal Protection Systems (TPS) Element, Rigid Materials Development task.

\section{B. Test Facility}

All tests were conducted at the Wright-Patterson Air Force Base Laser Hardened Materials Evaluation Laboratory $^{11}$ (LHMEL). The tests utilized the 15-kW LHMEL I laser, which was a continuous-wave, electric discharge, coaxial, $\mathrm{CO}_{2}$, gas laser. The materials tested were opaque to the laser's 10.6-micron output wavelength. The laser produced a calibrated, spatially-uniform "flat-top" heat flux profile beam. All tests reported here had a $4.65 \mathrm{~cm}$ (1.83 inch) beam diameter at the sample surface. Because the laser radiation was absorbed at the surface of the material, as opposed to in-depth, these tests were well-suited as screening tests.

The LHMEL facility was used to impart a known thermal load onto the material specimens via radiant heating. Because the environmental test chamber was made inert by a continual addition (purge) of nitrogen gas, comparisons of thermal protection capability, without the additional complication of surface recession, were made. Laser ablation, whereby the surface material liquefies and vaporizes due to the energy of the beam, was not expected nor was it observed for these tests. The materials would, however, pyrolyze due to in-depth thermal decomposition. In addition, the LHMEL facility had a high throughput capability allowing for many tests at a low cost, which was essential for quick screening testing of many materials.

Testing consisted of irradiating a model with a $\mathrm{CO}_{2}$ laser whose output irradiance was $\sim 450$ $\mathrm{W} / \mathrm{cm}^{2}$ for 60 seconds (Round 1) or 50 seconds (Round 2) to simulate an aerocapture maneuver. The laser spot size was $17 \mathrm{~cm}^{2}$. Thermocouple, radiometer (for surface temperature measurements), and video data were recorded during each run. After a minimum of one day's cool down, one sample of each material was exposed to a second heat pulse of $\sim 115 \mathrm{~W} / \mathrm{cm}^{2}$ for 100 seconds to simulate an entry environment. The models were photographed and weighed immediately before and after each test. Pre- and post-test height measurement, char depth, and photographs of sectioned models were also taken.

\section{Description of Materials}

A list of materials, vendors, test dates, and a brief description of the material are given in Table 1. For these Phase 1 (screening) tests, Round 1 testing occurred in May of 2010, and Round 2 of testing occurred in May of 2011.

Table 1. List of materials tested, vendors, dates, and a brief description of each material. 


\begin{tabular}{|c|c|c|c|c|}
\hline Name & Vendor & $\begin{array}{c}\text { Dual } \\
\text { Layer }\end{array}$ & $\begin{array}{c}\text { Test } \\
\text { Round }\end{array}$ & Description \\
\hline PICA & $\begin{array}{l}\text { Fiber } \\
\text { Materials } \\
\text { Inc (FMI) }\end{array}$ & no & $1 \& 2$ & Phenolic Impregnated Carbon Ablator \\
\hline 3DQP & Textron & yes & 1 & $\begin{array}{l}\text { Three-layer system consisting of a dense } \\
\text { outer mold, integration layer, and an } \\
\text { insulation layer. Materials were quartz } \\
\text { (silica) and phenolic. }\end{array}$ \\
\hline BPA-FG & Boeing & yes & 1 & $\begin{array}{l}\text { PICA-like material in honeycomb. } \\
\text { "Functionally graded" transition layer } \\
\text { between high- and low-density layers. }\end{array}$ \\
\hline $\mathrm{CC} /$ Calcarb & $\begin{array}{l}\text { Lockheed } \\
\text { Martin } \\
\text { Space } \\
\text { Systems } \\
\text { (LMSS) }\end{array}$ & yes & 1 & $\begin{array}{l}\text { Top layer was a composite of carbon } \\
\text { (graphite) in a carbon fiber reinforcement } \\
\text { matrix. Bottom layer was a carbon foam } \\
\text { made by Calcarb, Ltd. }\end{array}$ \\
\hline MonA & LMSS & yes & 1 & $\begin{array}{l}\text { A PICA-like "slurry" that has two different } \\
\text { densities being stacked in the honeycomb } \\
\text { and co-cured }\end{array}$ \\
\hline PIRAS-22 & $\begin{array}{l}\text { Applied } \\
\text { Research } \\
\text { Associates } \\
\text { (ARA) }\end{array}$ & no & 1 & $\begin{array}{l}\text { A polyimide-based ablator system } \\
\text { containing refractory reinforcing fibers and } \\
\text { refractory fillers. The ablator has several } \\
\text { reinforcement components one of which is } \\
\text { refractory silicon-carbide fibers. To reduce } \\
\text { final density it uses microballoon (MB) } \\
\text { fillers including developmental silicon- } \\
\text { carbide MBs and more common phenolic } \\
\text { MBs }\end{array}$ \\
\hline $\begin{array}{l}\text { Phencarb } \\
\text { P28/P15 }\end{array}$ & $\begin{array}{l}\text { ARA } \\
\text { Laboratory }\end{array}$ & yes & 1 & $\begin{array}{l}\text { PICA-like materials of different density } \\
\text { packed atop one another }\end{array}$ \\
\hline Graded PICA & FMI & yes & 2 & Variable density (graded) PICA \\
\hline $\mathrm{CBCF}$ & FMI & no & 2 & Carbon bonded carbon fiber \\
\hline Hoplon-22 & ARA & no & 2 & $\begin{array}{l}\text { A high-phenyl silicone ablator system } \\
\text { containing refractory reinforcing fibers and } \\
\text { a refractory filler. Both the fibers and } \\
\text { microballoon fillers include silicon carbide } \\
\text { materials of the same type as described for } \\
\text { PIRAS-22 }\end{array}$ \\
\hline Resolite-18 & ARA & no & 2 & Lightweight phenolic ablator \\
\hline
\end{tabular}

\section{Model and Model Holder Design}

All models were $5.08 \mathrm{~cm}$ (2.00 inch) in diameter and cylindrical in shape. The thickness of the PICA model was determined based on FIAT $^{12}$ predictions using the laser's irridation as an input energy term (multiplied by the surface absorptivity) in the surface energy balance. Ablation (B') tables were not used, and ablation was not expected because the models were immersed in a 
nitrogen environment. The maximum allowable bond line temperature (see Fig.1) was $250^{\circ} \mathrm{C}$ and the back face of the FRCI-12 was adiabatic. The model surface was allowed to re-radiate to a surrounding environment at $21^{\circ} \mathrm{C}$.

To have comparable test results between all materials tested, the mass of each model was requested to match the mass of the PICA model. Model length, therefore, varied for each material. Because each model had the same diameter, areal densities were therefore desired to be equivalent. It will be shown in the data analysis section, however, that areal density did, vary between materials depending on how well the vendors were able to match specifications.

1. Model Sizing for Round 1 Testing

FIAT predictions were made for a laser irradiation of $500 \mathrm{~W} / \mathrm{cm}^{2}$ for 180 seconds with a maximum bond line temperature of $250^{\circ} \mathrm{C}$. The predicted PICA thickness was $6.35 \mathrm{~cm}(2.5$ inch), with a resulting model mass of about 36 grams.

It was only much later after the test models had been made that it became known that the maximum laser duration for an intensity of $500 \mathrm{~W} / \mathrm{cm}^{2}$ was about 60 seconds. The decision was then made to drop the laser intensity to $450 \mathrm{~W} / \mathrm{cm}^{2}$ and irradiate the model for 60 seconds, which would be the new test conditions. However, with only about 1/3 of the desired (modeled) laser duration coupled with a loss in intensity of $50 \mathrm{~W} / \mathrm{cm}^{2}$, the test models would be severely oversized and bond line temperatures would not reach $250^{\circ} \mathrm{C}$.

2. Model Sizing for Round 2 Testing

FIAT predicted a required PICA thickness of $3.40 \mathrm{~cm}(1.34 \mathrm{inch})$ when the sample was exposed to a laser intensity of $440 \mathrm{~W} / \mathrm{cm}^{2}$ for a duration of 50 seconds with a maximum bond line temperature of $250^{\circ} \mathrm{C}$. The resulting model mass was about 18.93 grams. Round 2 testing of consisted of new PICA models and an entirely new set of vendor supplied materials.

3. Model Fabrication and Design

To help make the back wall of the material model adiabatic and to allow for thermocouple (TC) measurement, $1.27 \mathrm{~cm}(0.5 \mathrm{inch})$ of low density fibrous refractory composite insulation (FRCI-12) ${ }^{13}$ was attached to the back of each model using RTV-560 adhesive.

Dual-layer models had two different materials stacked together, or two different densities of the same material stacked together. Typically, these models had a co-cured transition layer between them as shown in Figure 1. A listing of the models tested is given in Table 2. 


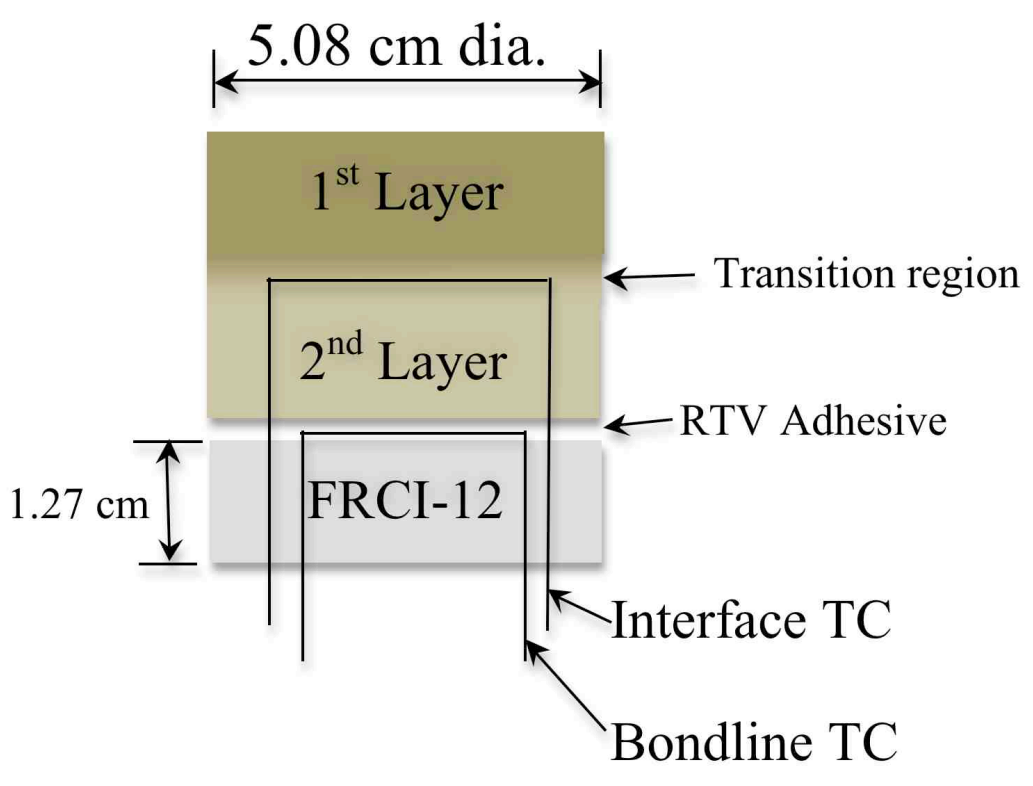

Figure 1. Assembly diagram of a typical dual-layer test model. Models with a single material of constant density did not have an interface TC.

\section{Model Holder Design}

The model holder is shown in Figure 2. The model (part \#1) sat on three graphite pins (part \#2) which were placed in slots on a graphite insert/sleeve (part \#3). Pins of various diameter could be used to offset variations in model diameter. However, all models for these tests were within specifications of $5.08 \mathrm{~cm}(2.00 \mathrm{inch})$ diameter and were able to use the same size diameter pins, $0.635 \mathrm{~cm}(0.25 \mathrm{inch})$. The pins were incorporated into the holder design to minimize lateral heat conduction from the model to the graphite insert/sleeve. A Mullite block (part \#4) housed the assembly and was placed on a moveable stage for laser beam alignment. The Mullite block was manufactured by Astro Met, Inc. of Cincinnati, Ohio. Finally, a back plate (part \#5) was used as a stop for the graphite insert/sleeve. 


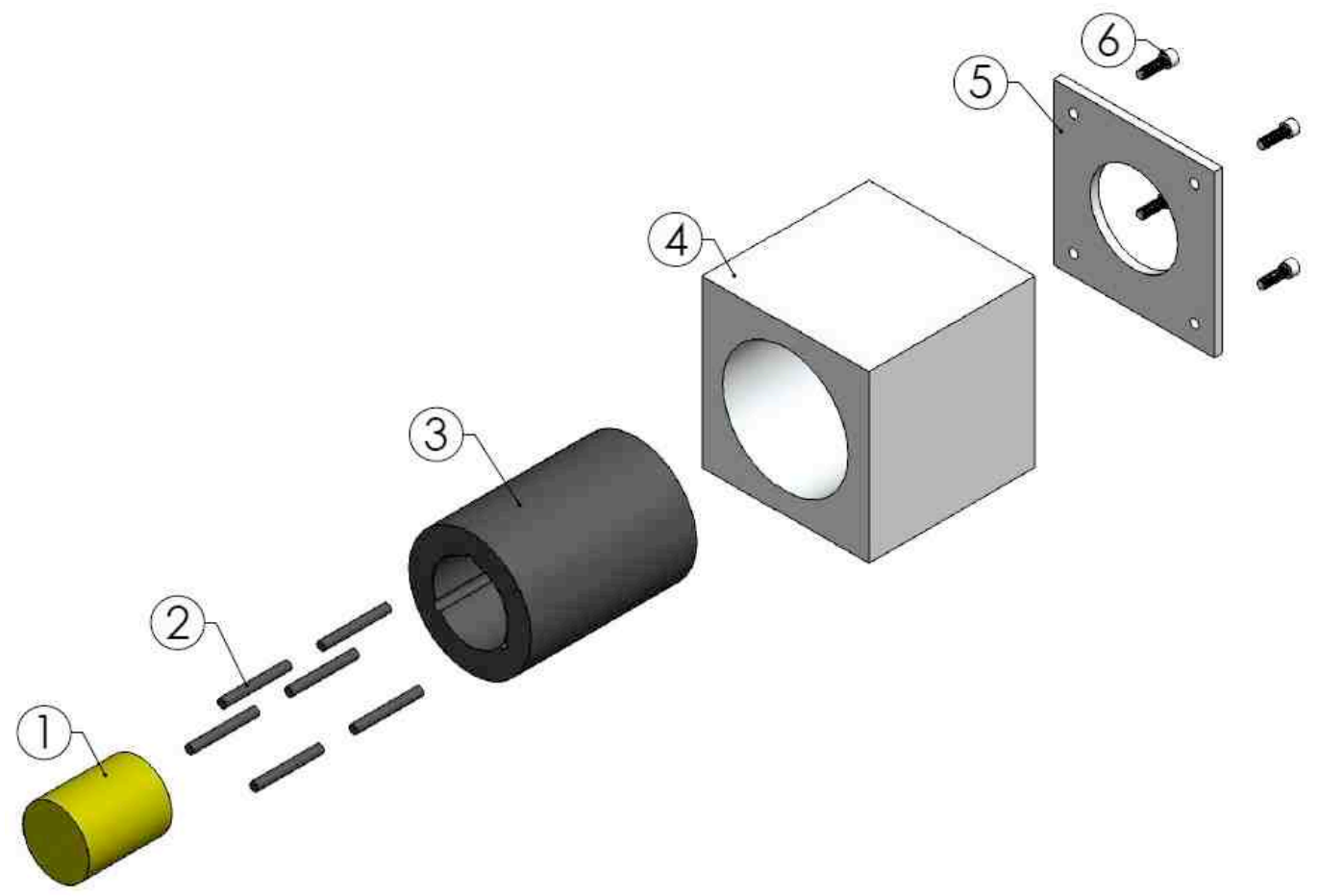

Figure 2. Assembly drawing of model holder.

\section{E. Test Procedure}

Test specimens were placed in the test holder, which was located inside the test box. To prevent oxidation and combustion of the test articles, a nitrogen feed line into the test box (see Figure 3) was added to ensure purging of oxygen from the system. In addition, the exhaust port on the test box was closed during, and for a few minutes after, each test run. It should be noted that for carbonaceous materials, these tests in nitrogen do not simulate ablative performance. The material response is only through conduction and pyrolysis.

Testing consisted of irradiating a model with the $\mathrm{CO}_{2}$ laser at an intensity of approximately $450 \mathrm{~W} / \mathrm{cm}^{2}$ to simulate the heat flux in an aerocapture environment, with a spot size of $17 \mathrm{~cm}^{2}$. The longest possible time that the laser could stay in continuous operation at this power was about 60 seconds, which was the test duration for Round 1 testing. To ensure a more consistent test duration, the test laser exposure time was reduced from 60 to 50 seconds for Round 2 testing. One sample of each material was exposed to a second heat pulse of $\sim 115 \mathrm{~W} / \mathrm{cm}^{2}$ for 100 seconds to simulate the entry environment. There was at least one day between tests of the first and second heat pulse. Thermocouple, radiometer, and video data were recorded during each run. All models were photographed and weighed immediately before and after each test. Pre- and posttest height measurement, char depth, and photographs of sectioned models were also taken after the conclusion of all testing. 




Figure 3. Plexiglass test box used to keep the test articles in a nitrogen-only environment

\section{Test Results from Round 1}

\section{A. Pre- and Post-Test Photographs}

\section{PICA}

Pre- and post-test photographs of the test specimens are shown in the following figures. All data are presented in the following section in Table 2. PICA test results were the benchmark to which test results from other models were compared. From Figure 4, it is apparent that PICA had a well-behaved pyrolysis and char response to the laser irradiation because the char layer exhibited no cracking, spallation, or pitting. Further, there was no evidence of swelling and the char layer was well defined.



a)

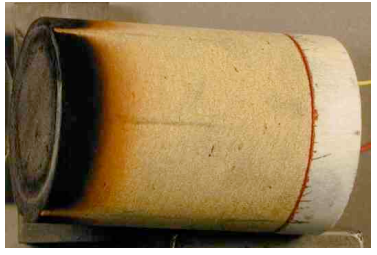

b)

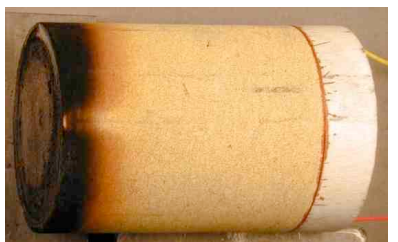

c)

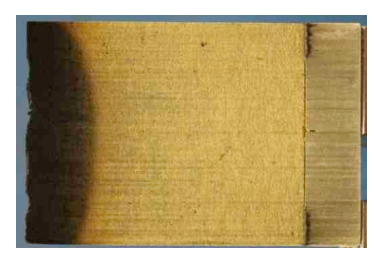

d)

Figure 4. PICA model 42527-3 a) pre-test b) post-test after 1st pulse c) post-test after 2nd pulse d) sectioned

\section{2. $3 D Q P$}

Test results from Textron's dual layer material, 3DQP, are presented in Figure 5. For this test series, 3DQP had a severe adverse reaction beginning at the very instant of laser beam irradiation. Material continually came off of the model and filled the test chamber with debris. It was unknown why this material would behave in such an unexpected manner given its history of ablative performance. Two models were tested, each with unfavorable results. These samples were not exposed to the second, simulated entry heat pulse. 


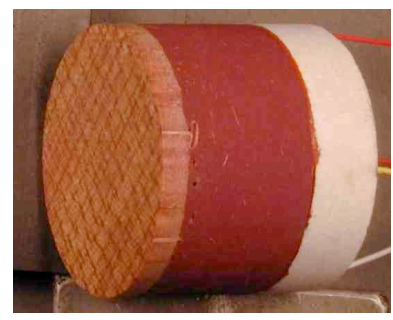

a)

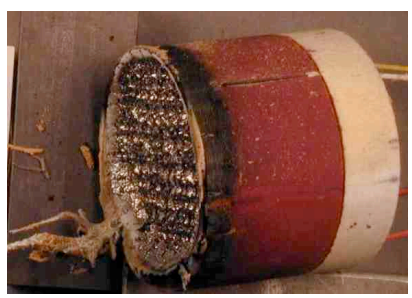

b)

Figure 5. 3DQP model A-02 a) pre-test and b) post-test photographs.

\section{3. $B P A F G$}

Figure 6 shows photographs from testing Boeing's functionally-graded, dual-layer, phenolic ablator, BPAFG. Overall, the material performed well, but it is apparent from these images (see circled region in Fig. 6a) that some of the low-density material adjacent to the honeycomb fell off during specimen manufacturing, possibly due to poor bonding to the honeycomb structure. The char layer was well-defined and the interface between layers has noticeable depth variations.

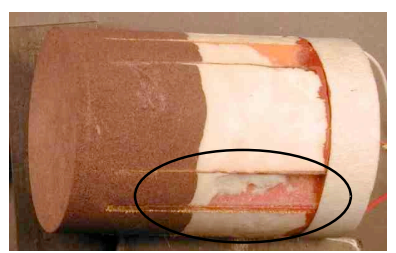

a)

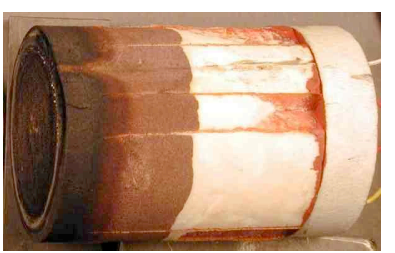

d)

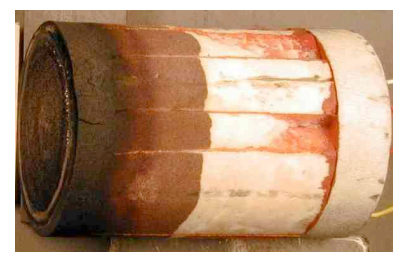

c)

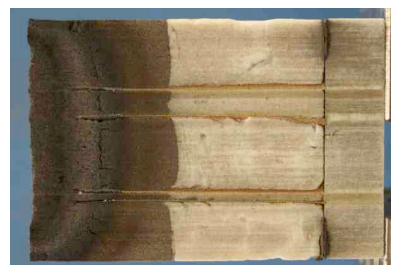

d)

Figure 6. BPAFG model A-03 a) pre-test b) post-test after 1st pulse c) post-test after 2nd pulse d) sectioned. The circled region of $6 \mathrm{a}$ ) illustrates a region on the test sample where material had fallen off prior to testing.

\section{CC/Calcarb}

Figure 7 shows photographs of the test results from Lockheed Martin's Carbon-Carbon atop Calcarb dual layer model VF5000-01. Being a fully carbon material, no char layer is apparent in the figure. As expected, the carbon-carbon top layer shows very little effect from the laser irradiation.

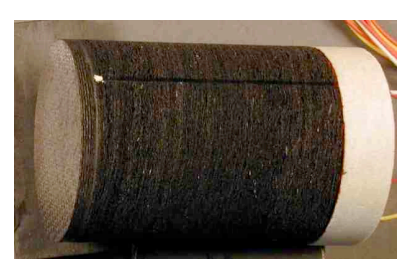

a)

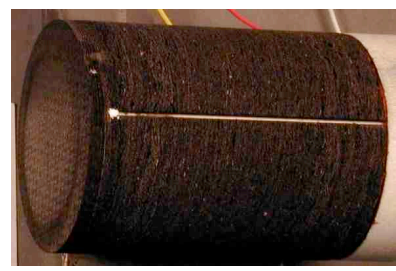

b)

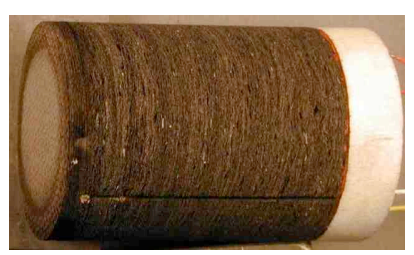

c)

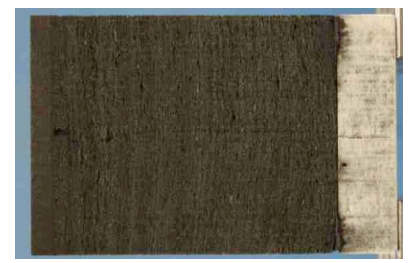

d)

Figure 7. CC/Calcarb model VF5000-01 a) pre-test b) post-test after 1st pulse c) post-test after 2nd pulse d) sectioned

\section{MonA}

Figure 8 shows photographs of the test results from Lockheed Martin's material MonA, model \#A1. The images show MonA had a well-behaved pyrolysis and char response to the laser irradiation, with no evidence of swelling. Interestingly, as shown in sectioned model photograph (Fig. 8d), the char layer appears to have multiple layers based on distinct color bands. These 
bands were probably due to the differing levels of phenolic decomposition, and they appeared for all (single and dual laser pulse exposure) of the MonA tested models. The dual-layer interface also shows some depth variation, but this was not expected to affect the test results.

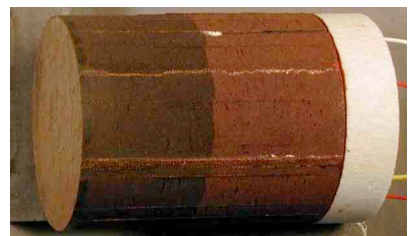

a)

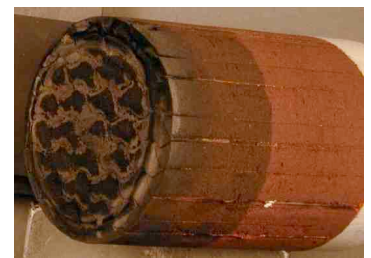

b)

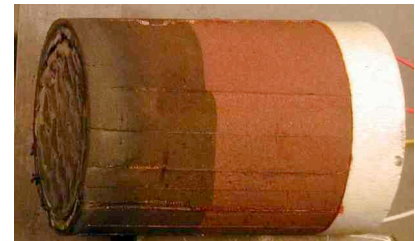

c)

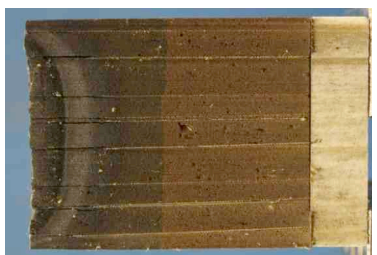

d)

Figure 8. Lockheed Martin MonA model A1 a) pre-test b) post-test after 1st pulse c) posttest after 2nd pulse d) sectioned

\section{Phencarb P28/P15}

Figure 9 shows photographs of the test results from ARA's Phencarb dual layer stackup material consisting of P28 over P15, model \#9011. It was observed that along its outer surface, the dual layer interface was visually apparent (Fig 9a-9d). The photographs show P28/P15 had a well-behaved pyrolysis and char response to the laser irradiation, with no evidence of swelling. However, the char layer appears to have some cracking as shown in sectioned model photograph (see circled region in Fig. 9d).

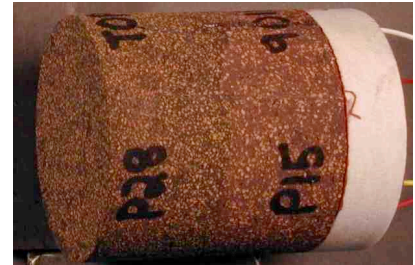

a)



b)

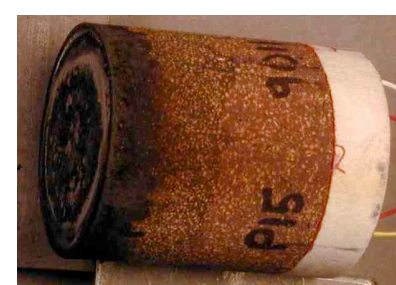

c)

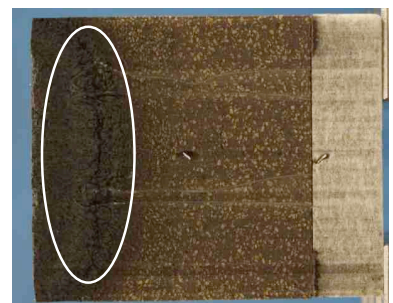

d)

Figure 9. ARA P28/P15 model 9011 a) pre-test b) post-test after 1st pulse c) post-test after 2nd pulse d) sectioned. The circled region highlights some cracking found in the char layer.

\section{PIRAS-22}

Figure 10 shows photographs of the test results from ARA's PIRAS-22, model \#9011. The images show PIRAS-22 had a well-behaved pyrolysis and char response to the laser irradiation. However, the char layer did expand (swell) appreciably during the testing. The sectioned model photograph (Fig. 10d) shows the char layer to be well defined.

Swell was not considered to be a critical issue for material down-selection because to some extent it could help offset recession in an ablative environment. However, volume change (shrinkage or swelling) can cause issues such as cracking or shape irregularity as the piece size is increased. 


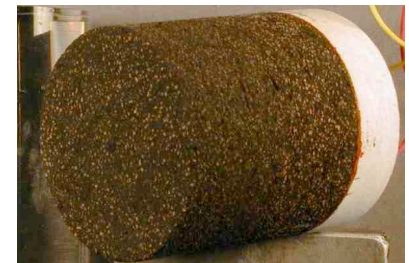

a)

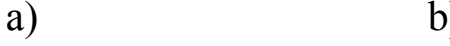

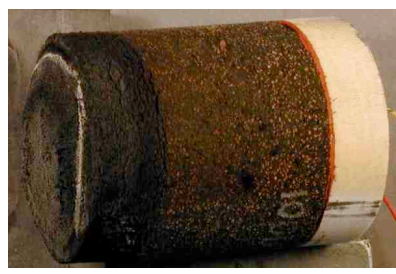

b)

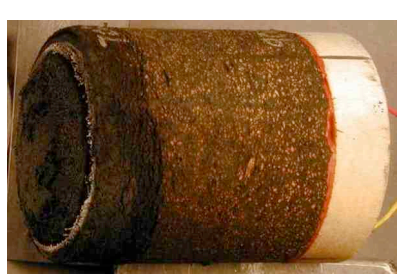

c)

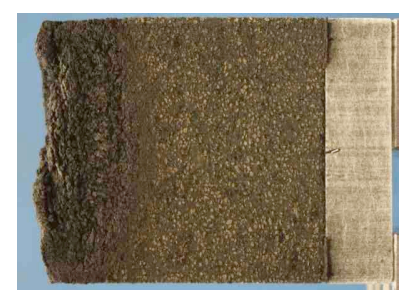

d)

Figure 10. ARA PIRAS-22 model 9001 a) pre-test b) post-test after 1st pulse c) post-test after 2 nd pulse d) sectioned

\section{B. Summary of Round 1 Data}

A summary of the data from Round 1 testing is given in Table 2. Results after a second laser exposure test are bolded and the model names are given the suffix "Char" to indicate that the model had previously been charred by exposure to the first laser pulse.

\section{Surface recession}

The models were tested in a nitrogen-rich environment to avoid the effects of ablation. However, surface recession (shrinkage) and char swelling occurred for some models. Using a depth gauge, post-test height measurements were averaged from four radial, evenly spaced measurement locations on the top of the model. These measurements were taken at NASA Ames after the completion of testing. The results are given in Table 2. Figures 11 and 12 show the averaged results from the first laser pulse (simulating aerocapture) and the averaged results for the second laser pulse (simulating entry). The amount of recession was determined by the difference in pre- and post-test height measurements. The accuracy of height and recession measurements was $\pm 0.025 \mathrm{~cm}(0.010$ inch $)$ based on repeatability of the measurements.

Height measurements were taken before testing and after a model's final laser exposure (first or second pulse). Consequently, initial height and recession after the first laser exposure data are not reported for the dual-pulse models (see Table 2).

PICA, Phencarb P28/P15, and CC/Calcarb did not experience any surface recession. 3DQP experienced catastrophic behavior with what appeared to be virgin material coming off the surface. MonA and BPAFG did experience a small amount of shrinkage $\sim 0.1 \mathrm{~cm}(0.04 \mathrm{in})$. The only material to show significant swell was PIRAS-22 at approximately $0.7 \mathrm{~cm}(0.276 \mathrm{in}$.), which was easily noticeable when the tested models were observed. 
Table 2. Summary of Round 1 test data. Data in bold and marked with the suffix "Char" are the test results for models that had previously been exposed to the first laser conditions (to simulate an aerocapture maneuver) and undergone a second laser exposure (to simulate planetary entry).

\begin{tabular}{|c|c|c|c|c|c|c|c|c|c|}
\hline Name & \begin{tabular}{c|} 
Laser \\
Duration, $\mathrm{s}$
\end{tabular} & $\begin{array}{c}\text { Laser } \\
\text { Intensity, } \\
W / \mathrm{cm}^{2}\end{array}$ & $\begin{array}{c}\text { Heat Load, } \\
\mathrm{kJ} / \mathrm{cm}^{3}\end{array}$ & $\begin{array}{c}\text { Max. } \\
\text { Interface } \\
\text { Temp, }{ }^{\circ} \mathrm{C}\end{array}$ & $\begin{array}{c}\text { Max. } \\
\text { Bondline } \\
\text { Temp, }{ }^{\circ} \mathrm{C}\end{array}$ & $\begin{array}{c}\text { \%Virgin } \\
\text { Remaining }\end{array}$ & $\begin{array}{c}\text { Recession, } \\
\text { cm }\end{array}$ & $\begin{array}{c}\text { Initial } \\
\text { Model } \\
\text { Mass, g }\end{array}$ & $\begin{array}{c}\text { Mass } \\
\text { Loss, g }\end{array}$ \\
\hline PICA 42527-3 & 60.1 & 447 & 26.8 & $\mathrm{n} / \mathrm{a}$ & 41 & - & - & 51.197 & 1.51 \\
\hline PICA 42527-3 Char & 100.0 & 117 & 11.7 & $\mathbf{n} / \mathbf{a}$ & 45 & 72.9 & 0.011 & 49.928 & 0.15 \\
\hline PICA 42527-4 & 57.6 & 453 & 26.1 & $\mathrm{n} / \mathrm{a}$ & 46 & 73.1 & 0.007 & 51.567 & 1.28 \\
\hline 3DQP-A-01 & 46.5 & 448 & 20.8 & 2845 & 71 & 59.8 & 0.350 & 62.129 & 12.43 \\
\hline 3DQP-A-02 & 28.8 & 459 & 13.2 & $\mathrm{n} / \mathrm{a}$ & 56 & 75.1 & 0.350 & 63.362 & 9.90 \\
\hline BPAFG-A-01 & 52.8 & 437 & 23.1 & 75 & 49 & 67.9 & 0.182 & 65.124 & 4.61 \\
\hline BPAFG-A-02 & 56.9 & 444 & 25.3 & 76 & 46 & 67.1 & 0.122 & 66.304 & 3.62 \\
\hline BPAFG-A-03 & 57.5 & 453 & 26.1 & 74 & 49 & - & - & 65.318 & 5.37 \\
\hline \begin{tabular}{|l} 
BPAFG-A-03 Char \\
\end{tabular} & 100.1 & 114 & 11.4 & 83 & 46 & 58.5 & 0.158 & 60.190 & 1.31 \\
\hline CC/CALCARB VF5000-01 & 57.0 & 448 & 25.5 & 1991 & 75 & - & & 64.352 & 0.28 \\
\hline CC/CALCARB VF-5000-01 Char & 100.1 & 119 & 11.9 & 1322 & 55 & 100.0 & -0.016 & 64.155 & 0.09 \\
\hline CC/CALCARB VF-5000-02 & 57.6 & 442 & 25.4 & 2069 & 60 & 100.0 & 0.008 & 62.749 & 0.35 \\
\hline CC/CALCARB VF-5000-03 & 57.6 & 454 & 26.1 & 2004 & 60 & 100.0 & -0.010 & 63.048 & 0.26 \\
\hline LM-MONA-A1 & 57.6 & 445 & 25.6 & 77 & 51 & - & - & 62.782 & 3.19 \\
\hline LM-MONA-A1 Char & 100.1 & 114 & 11.4 & 87 & 43 & 69.9 & 0.129 & 59.829 & 0.65 \\
\hline LM-MONA-A2 & 57.5 & 453 & 26.0 & 77 & 53 & 73.0 & 0.116 & 62.575 & 2.98 \\
\hline LM-MONA-A4 & 57.5 & 451 & 25.9 & 81 & 48 & 72.1 & 0.125 & 62.707 & 3.27 \\
\hline P28/P15-9011 & 57.6 & 444 & 25.6 & 67 & 39 & - & - & 61.106 & 4.13 \\
\hline \begin{tabular}{|l} 
P28/P15-9011 Char \\
\end{tabular} & 100.0 & 116 & 11.6 & 128 & 47 & 67.7 & -0.009 & 57.224 & 1.38 \\
\hline P28/P15-9012 & 53.6 & 433 & 23.2 & 56 & 36 & 74.4 & -0.030 & 62.757 & 3.77 \\
\hline P28/P15-9013 & 57.6 & 448 & 25.8 & 63 & 39 & 76.6 & -0.003 & 61.280 & 4.14 \\
\hline \begin{tabular}{|l} 
PIRAS-22 9001 \\
\end{tabular} & 60.1 & 431 & 25.9 & $\mathrm{n} / \mathrm{a}$ & 40 & - & - & 51.831 & 3.62 \\
\hline \begin{tabular}{|l} 
PIRAS-22-9001 Char \\
\end{tabular} & 100.1 & 116 & $\mathbf{1 1 . 6}$ & $\mathbf{n} / \mathbf{a}$ & 41 & 77.9 & -0.683 & 48.448 & 0.36 \\
\hline PIRAS-22-9002 & 50.4 & 435 & 21.9 & $\mathrm{n} / \mathrm{a}$ & 40 & 80.2 & -0.706 & 52.631 & 2.93 \\
\hline PIRAS-22-9003 & 57.6 & 446 & 25.7 & $\mathrm{n} / \mathrm{a}$ & 36 & 80.0 & -0.721 & 51.785 & 3.24 \\
\hline
\end{tabular}




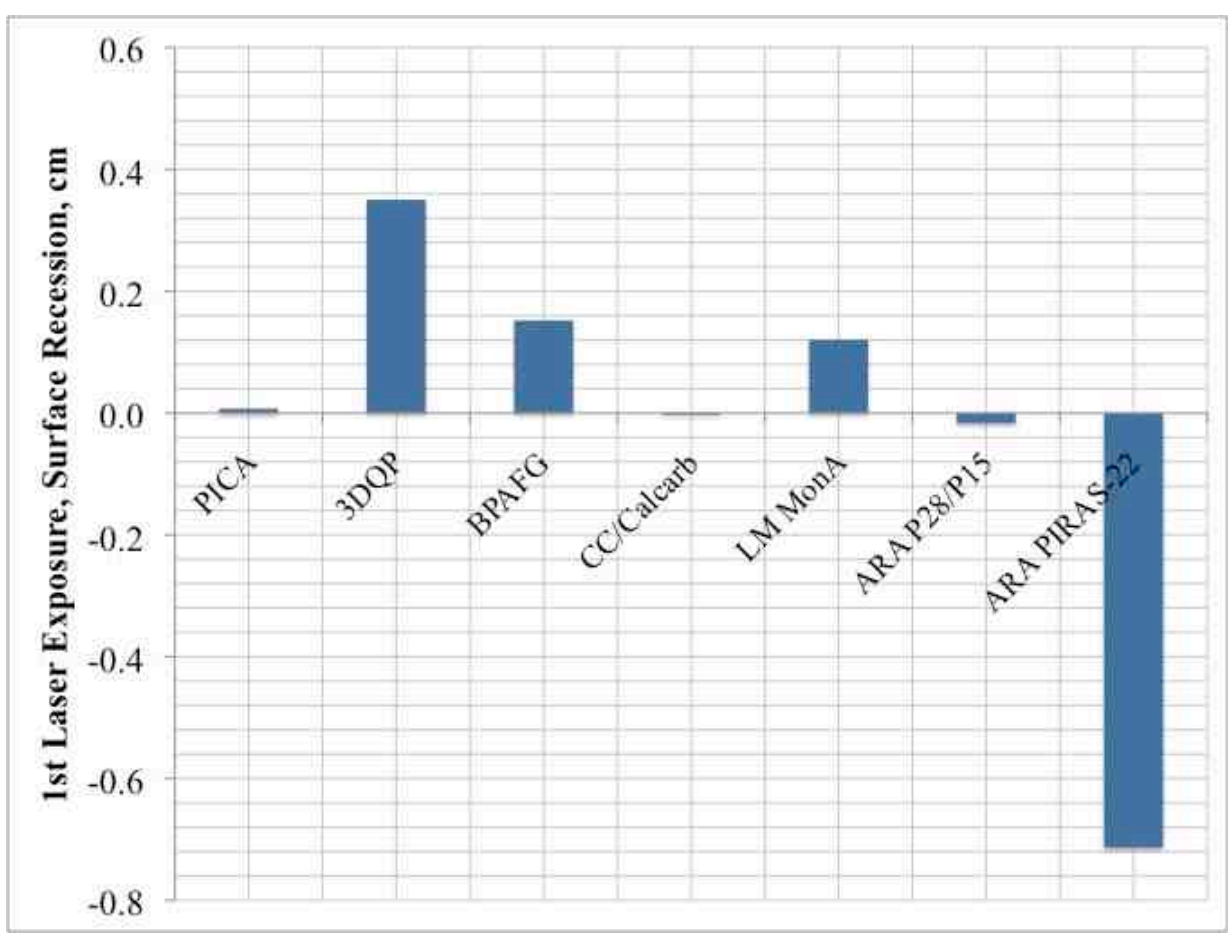

Figure 11. Surface recession of single laser pulse tested materials. Negative values indicate surface expansion (swell).

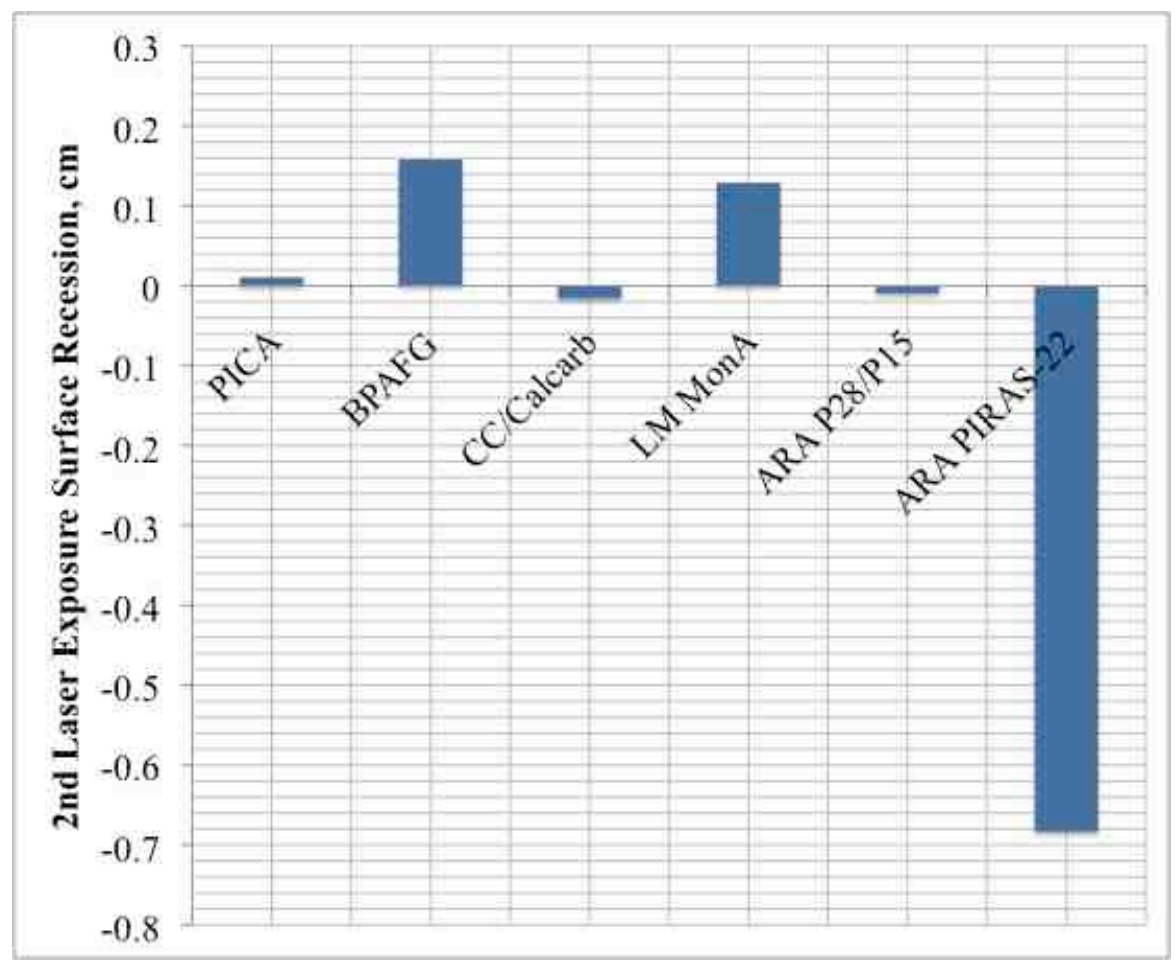

Figure 12. Surface recession for Round 1 tested materials after the second laser exposure. Negative values indicate surface expansion (swell). 


\section{Areal Density}

For comparable test results, the mass of each model was requested to match the PICA model mass of approximately 36 grams. Because each model had the same diameter, $5.08 \mathrm{~cm}$, model thickness varied to keep the areal density (and mass) constant. Areal densities were calculated by dividing initial model mass (not including FRCI-12 back plate or TC) by surface area (20.268 $\mathrm{cm}^{2}$ ). A comparison of the averaged areal density for each virgin material is given in Figure 13. Of the materials tested, BPAFG had the highest areal density, $1.94 \mathrm{~g} / \mathrm{cm}^{2}$, which was about $11 \%$ greater than PICA. The dispersion in areal density between materials exists due to how well each vendor was able to meet the design specification for model mass to be 36 grams.

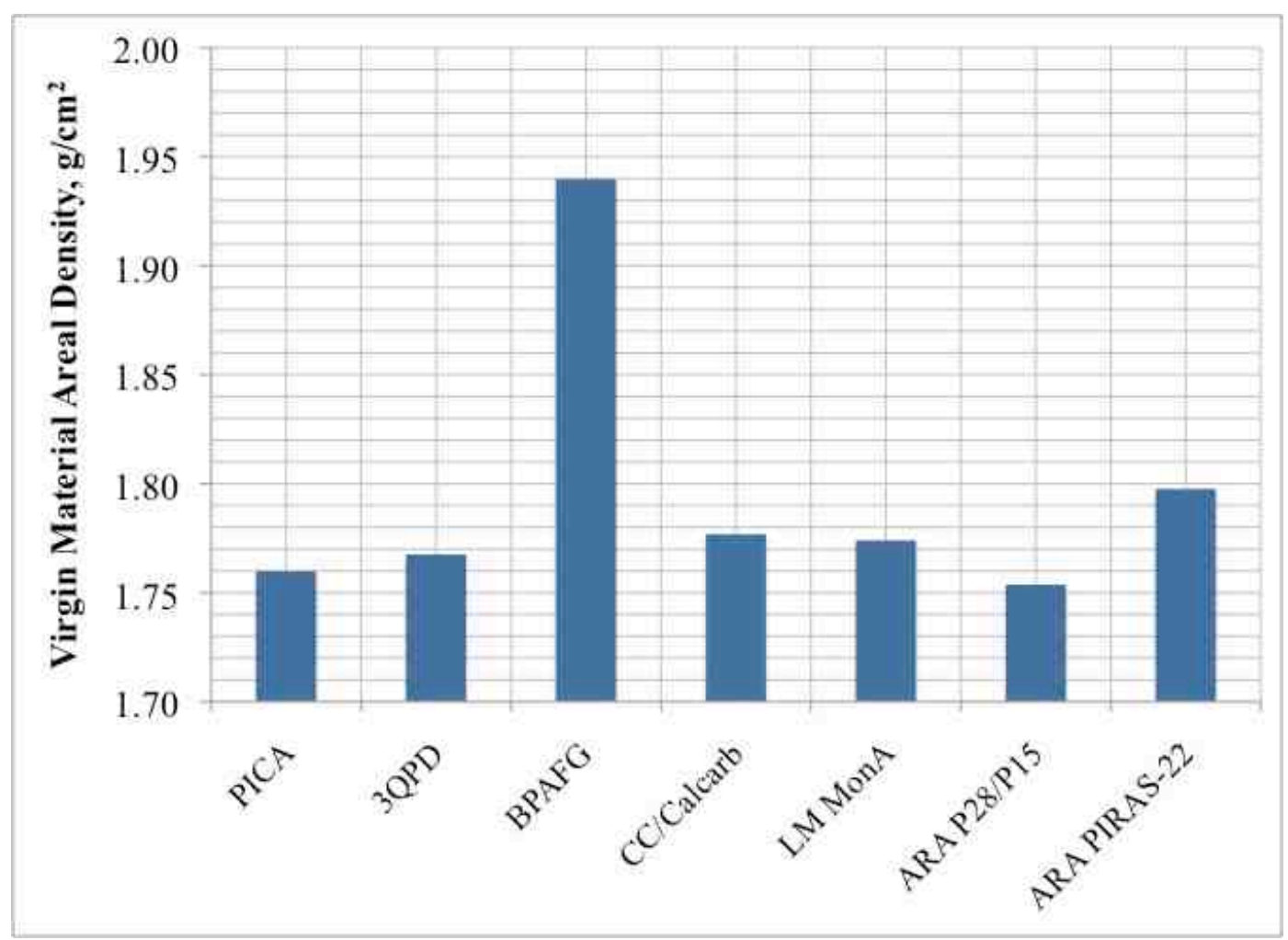

Figure 13. Averaged areal density of Round 1 tested materials

\section{Mass loss}

The total initial model mass (including FRCI-12 back plate TC wires) and mass loss data are given in Table 2. Mass measurements were taken immediately before and after each test because atmospheric water absorption would allow model mass to vary. The results are shown in Figure 14 for the first laser exposure and Figure 15 for the second laser exposure. Atmospheric water absorption was especially evident with post-tested models, whose mass was observed to slowly drift upwards for an hour or more after being tested. It was for this reason that mass loss data were reported with less accuracy (significant figures).

As the testing baseline, PICA, when tested from its virgin state, had an average mass loss of 1.395 grams, and the charred PICA sample (second laser pulse) lost 0.15 grams. All other materials tested, with the exception of Carbon-carbon/Calcarb, had greater mass loss for both virgin and charred (second-pulse) samples. The data are given in Table 2. CC/Calcarb had an 
average mass loss of 0.30 grams for the virgin material and 0.09 grams for the charred sample, second-pulse test.

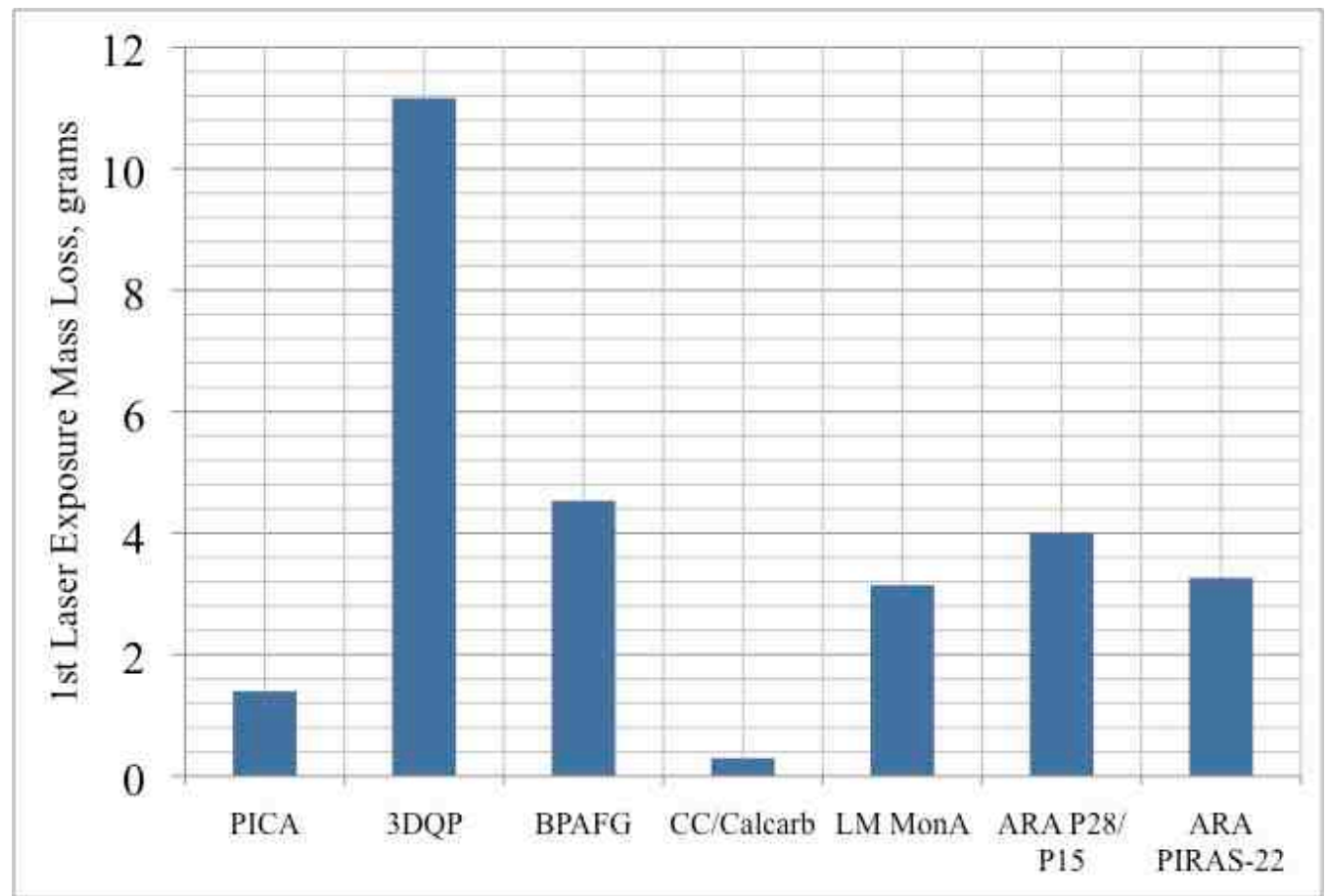

Figure 14. Mass loss of Round 1 materials after $1^{\text {st }}$ laser exposure

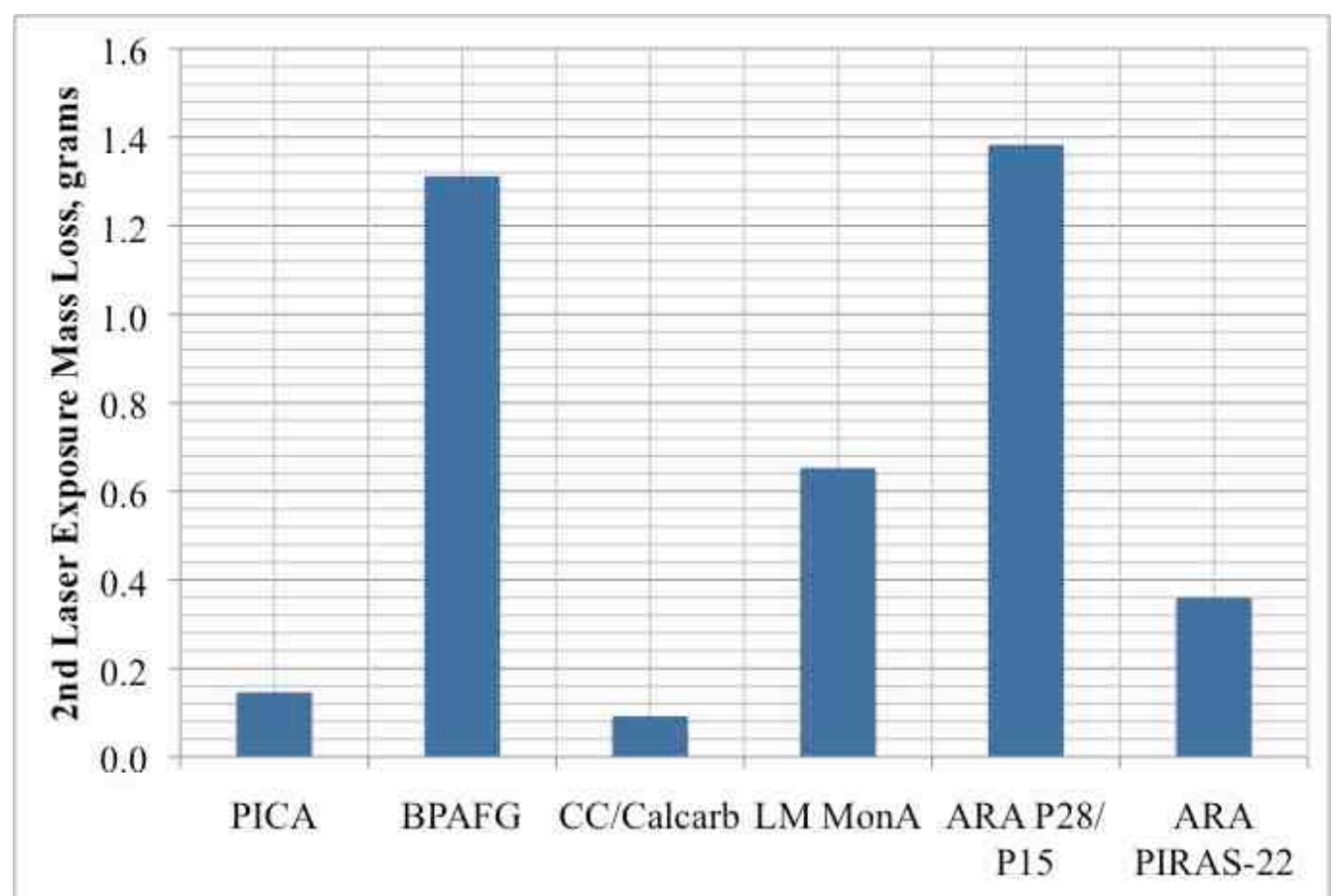

Figure 15. Mass loss of Round 1 materials after 2nd laser exposure (note: 3DQP was not tested for a second laser exposure) 


\section{Percentage virgin material remaining}

One way of looking at char depth was by percentage of virgin material remaining. Using a sample sectioned along the cylinder axis, percentage virgin material remaining was determined by measuring, based on visual inspection, the distance from the bond line to the beginning of pyrolysis edge and then dividing this length by the original model thickness. This was a subjective test because the exact location of the beginning of pyrolysis edge can only be determined by knowing the local density. The pyrolysis edge is usually defined as the location where the local density is equivalent to $98 \%$ of the density of virgin material. Nevertheless, this test may give a qualitative indication of the depth of thermal decomposition for a material. The results are given in Table 2 .

Figure 16 shows the results for all of the models. Values are given as a percentage because model thickness varied between materials and model thickness was determined by the requirement that each material had an equivalent areal density.

As the benchmark material, PICA had values of $73.1 \%$ for the virgin material tested and $72.9 \%$ for the charred. Being a carbon-only material, CC/Calcarb did not exhibit any pyrolysis zone and thus had $100 \%$ of virgin material remaining for all models tested. PIRAS-22 had the next highest values at $80.1 \%$ for virgin material tested, and $77.9 \%$ for charred. Phencarb P28/P15 had values slightly better than PICA for the virgin material tested at $75.5 \%$ and slightly worse for the charred material at $67.7 \%$. MonA had values similar to PICA for virgin material tested and slightly worse at $69.9 \%$ for charred material. BPAFG had worse results than PICA, with values of $67.5 \%$ for virgin material tested and $58.5 \%$ for charred material tested.

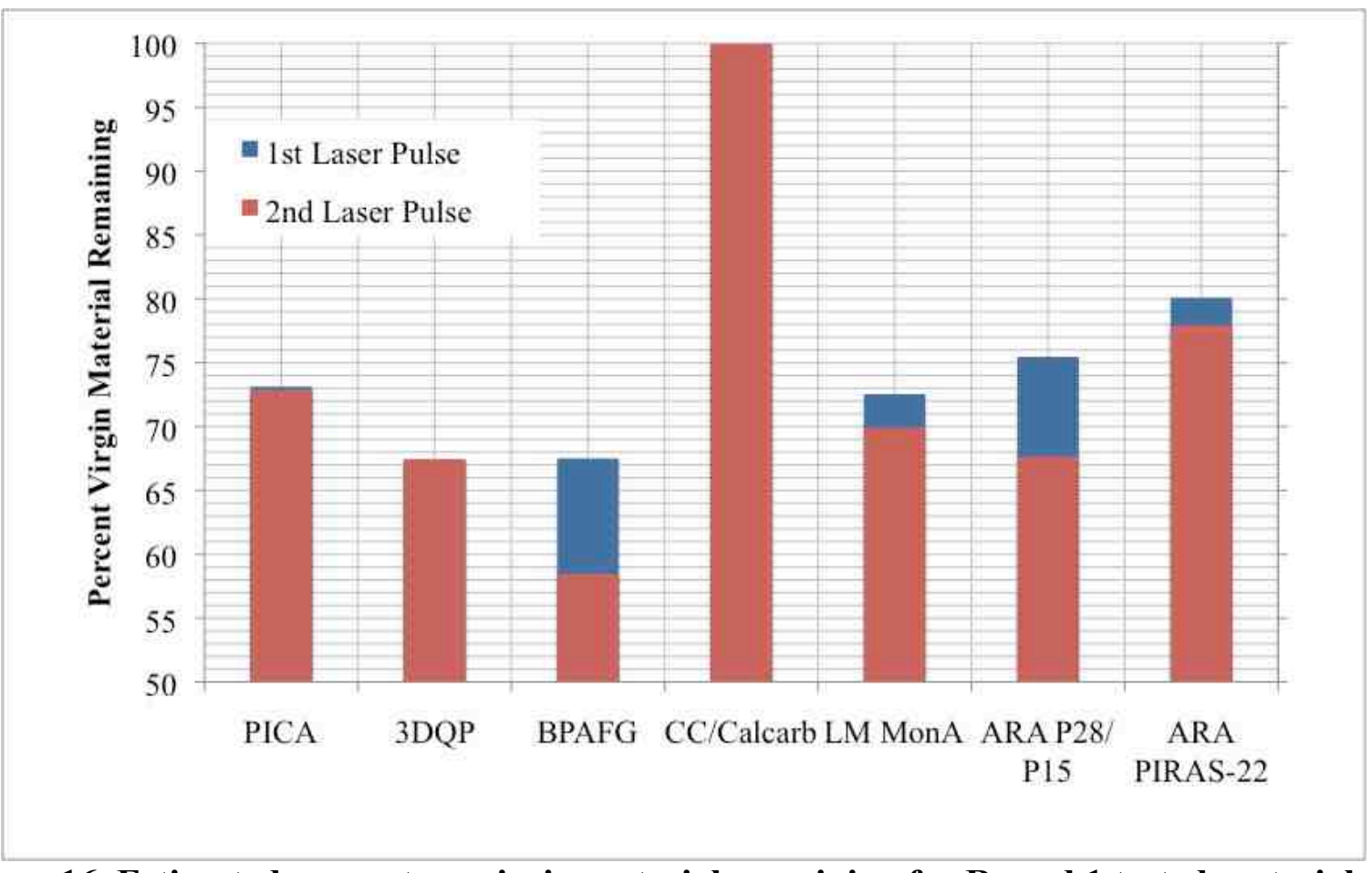

Figure 16. Estimated percentage virgin material remaining for Round 1 tested materials

\section{Maximum bond line temperature}

Maximum bond line temperatures for all models tested are given in Table 2. Figure 17 shows a comparison of the averaged maximum bond line TC temperature recorded for the models after 
the first laser pulse exposure. Although the laser duration was for the first exposure was set to 60 seconds, the laser would often shut down a few seconds prior to this (see Table 2). Because heat load had such a strong influence on bond line temperature, the material's averaged heat load $\left[\mathrm{kJ} / \mathrm{cm}^{2}\right]$ for the tests is given above each bar. With the exception of 3DQP, for which the laser had to be manually shut off early, the average heat load varied by no more than $6.3 \%$ for each material, and average laser intensity varied by no more than $6.4 \%$. As shown in Fig. 16, only ARA's P28/P15 and ARA's PIRAS-22 were able to achieve a lower average bond line temperature. Note that the maximum bond line temperature from the second laser pulse had a span of only $16^{\circ} \mathrm{C}$, with most of the materials within $6^{\circ} \mathrm{C}$. Given this narrow range, no further data analysis was performed.

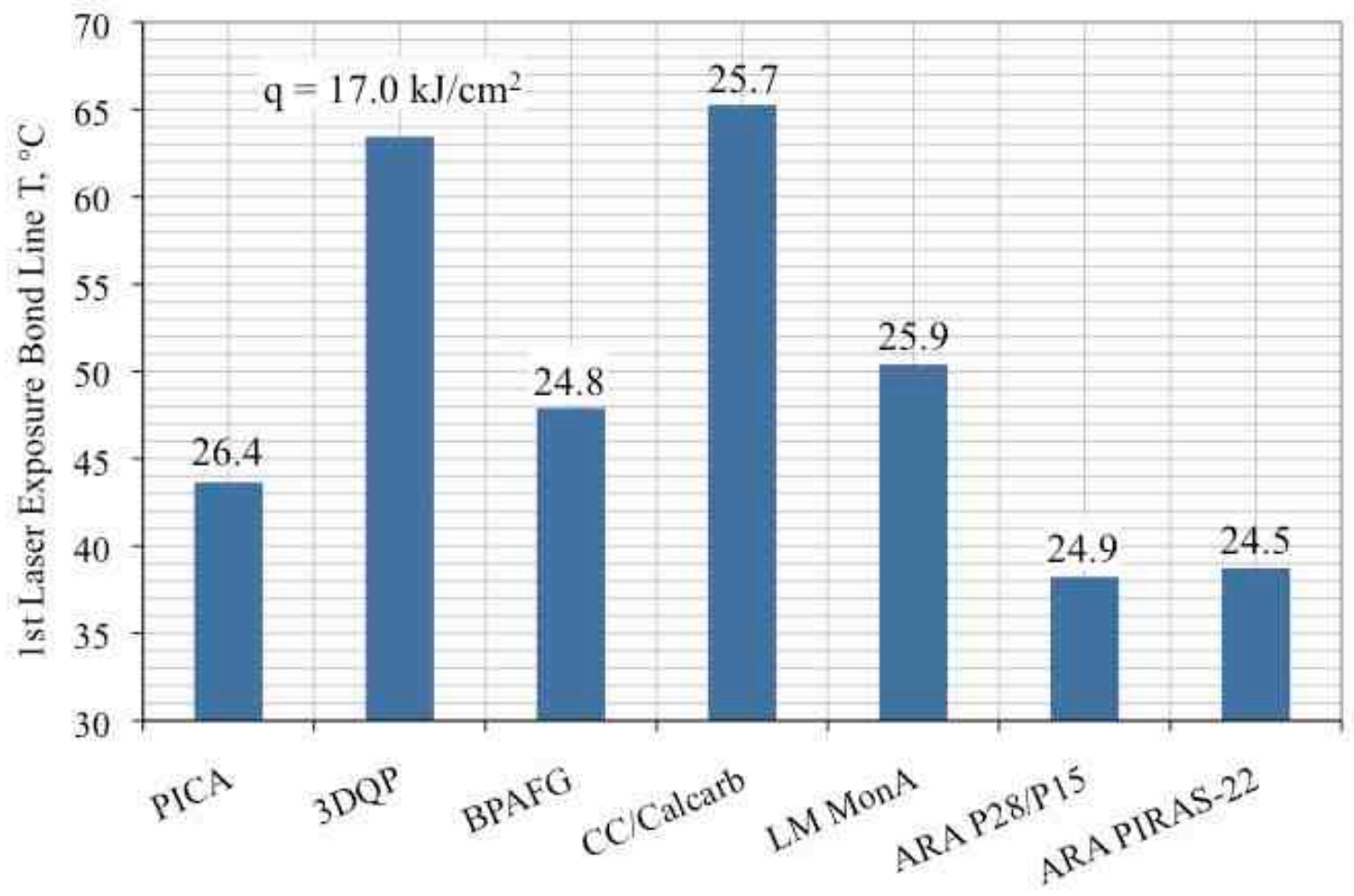

Figure 17. Averaged maximum bond line temperature and averaged heat load $\left[\mathrm{kJ} / \mathrm{cm}^{2}\right]$ for models after being exposed to the first laser pulse.

\section{Test Results from Round 2}

\section{A. Pre- and Post-Test Photographs}

\section{PICA}

The results for PICA are identical in appearance to those found in Round 1 testing (see Fig. 4). The results from Round 2 testing are shown in Figure 18. 


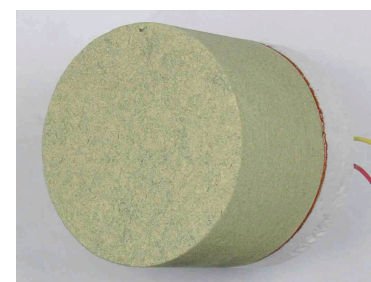

a)

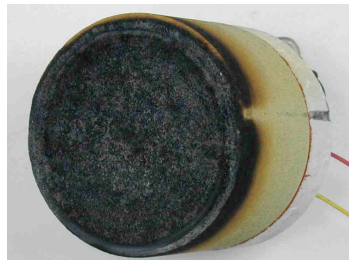

b)



c)

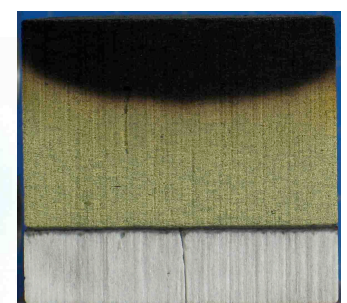

d)

Figure 18. PICA model L-RR a) pre-test b) post-test after 1st pulse c) post-test after 2nd pulse d) sectioned

\section{Round 2 vendor materials}

The results for Graded PICA, Hoplon-22, Resolite-18, and CBCF are shown in Figures 19-22.

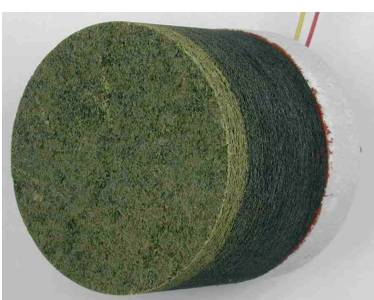

a)



b)



c)

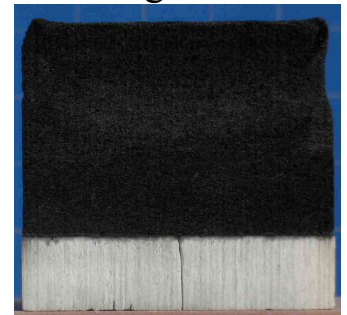

d)

Figure 19. Graded PICA model 01 a) pre-test b) post-test after 1st pulse c) post-test after 2nd pulse d) sectioned

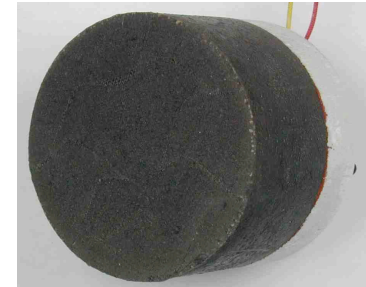

a)



b)

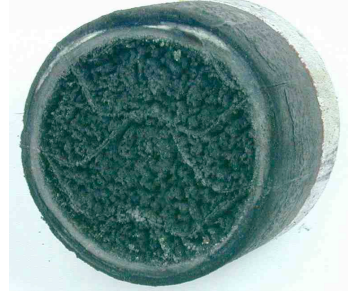

c)

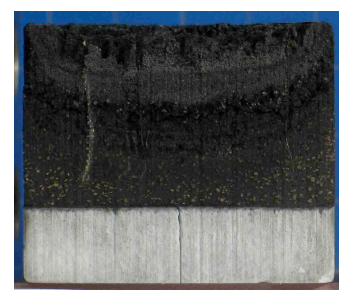

d)

Figure 20. Hoplon-22 model 01 a) pre-test b) post-test after 1st pulse c) post-test after 2nd pulse d) sectioned



a)

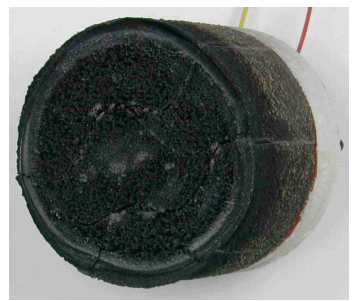

b)



c)

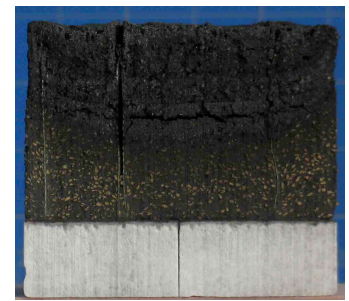

d)

Figure 21. Resolite-18 model 02 a) pre-test b) post-test after 1st pulse c) post-test after 2nd pulse d) sectioned 


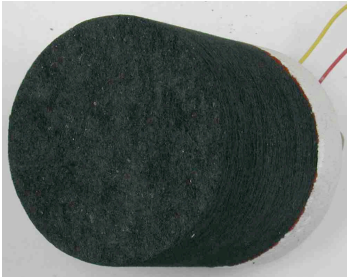

a)

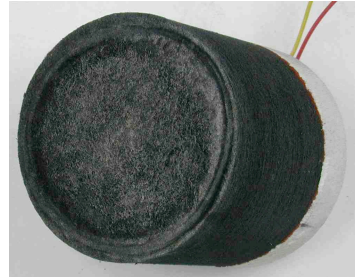

b)

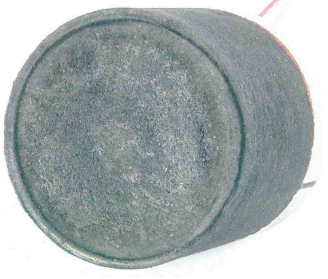

c)

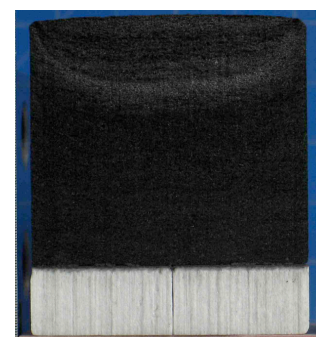

d)

Figure 22. CBCF model 02 a) pre-test b) post-test after 1st pulse c) post-test after 2nd pulse d) sectioned

\section{B. Summary of Round 2 Data}

A summary of the data from Round 2 testing is given Table 3. Results after a second laser exposure test are bolded and the model names are given the suffix "Char" to indicate that the model had previously been charred by exposure to the first laser pulse.

Table 3. Summary of Round 2 test data. Data marked with the suffix "Char" are test results for models that had previously been exposed for 50 seconds to the first laser conditions (to simulate an aerocapture maneuver) and undergone a second laser exposure for 100 seconds (to simulate planetary entry).

\begin{tabular}{|l|r|r|r|r|r|r|r|}
\hline Name & $\begin{array}{r}\text { Laser } \\
\text { Intensity, } \\
\mathbf{W} / \mathbf{c m}^{2}\end{array}$ & $\begin{array}{c}\text { Max } \\
\text { Bondline } \\
\text { Temp, } \\
{ }^{\circ} \mathbf{C}\end{array}$ & $\begin{array}{c}\text { Initial } \\
\text { Mass, } \mathbf{g}\end{array}$ & $\begin{array}{c}\text { Areal } \\
\text { Density } \\
\mathbf{g} / \mathbf{c m}^{2}\end{array}$ & $\begin{array}{c}\text { Mass } \\
\text { Loss, } \mathbf{g}\end{array}$ & $\begin{array}{c}\text { Heatload, } \\
\mathbf{k J} / \mathbf{c m}^{2}\end{array}$ & $\begin{array}{c}\text { \%Virgin } \\
\text { Remaining }\end{array}$ \\
\hline PICA_1 & 449.4 & 95.3 & 32.249 & 0.955 & 1.279 & 22.5 & \\
\hline PICA_1Char & 116.3 & 107.4 & 30.970 & & 0.102 & 11.6 & 60.6 \\
\hline PICA_2 & 453.8 & 91.2 & 32.674 & 0.958 & 1.244 & 22.7 & 60.7 \\
\hline Graded PICA_01 & 444.0 & 384.0 & 27.615 & 0.730 & 2.625 & 22.2 & \\
\hline Graded PICA_01 Char & 116.9 & 151.5 & 24.990 & & 0.056 & 11.7 & 42.7 \\
\hline Graded PICA_02 & 454.9 & 150.1 & 27.533 & 0.734 & 1.087 & 22.8 & 53.1 \\
\hline Hoplon-22_01 & 449.4 & 88.7 & 33.784 & 1.030 & 4.531 & 22.5 & \\
\hline Hoplon-22_01 Char & 116.0 & 190.8 & 29.253 & & 1.046 & 11.6 & 27.8 \\
\hline Hoplon-22_02 & 450.2 & 91.5 & 34.139 & 1.042 & 4.438 & 22.6 & 35.9 \\
\hline Resolite-18_02 & 455.4 & 85.2 & 30.467 & 0.886 & 3.699 & 22.8 & \\
\hline Resolite-18_02 Char & 114.9 & 115.3 & 26.768 & & 0.557 & 11.5 & 29.2 \\
\hline Resolite-18_03 & 451.2 & 85.1 & 31.673 & 0.926 & 3.661 & 22.6 & 44.7 \\
\hline CBCF_01 & 449.0 & 65.9 & 31.944 & 0.920 & 0.849 & 22.4 & \\
\hline CBCF_01 Char & 115.7 & 58.8 & 31.095 & & 0.174 & 11.6 & 60.7 \\
\hline CBCF_02 & 450.5 & 63.5 & 31.479 & 0.925 & 0.939 & 22.6 & 61.6 \\
\hline
\end{tabular}

\section{Surface recession}

The models were tested in a nitrogen-rich environment to avoid the effects of ablation. Using vernier calipers, pre- and post-test thickness measurements were made, and recession was defined as the difference between initial and final thickness values. The accuracy of these measurements was $\pm 1.0 \mathrm{~mm}(0.039 \mathrm{inch})$ based on repeatability and softness of the char to the caliper. Relative to this degree of accuracy, none of the models showed any significant shrinkage (recession) or swell. 


\section{Areal Density}

The areal density for each model prior to testing is given in Table 3 and shown in Figure 23. Graded PICA, with a value of $\sim 0.73 \mathrm{~g} / \mathrm{cm}^{2}$, was substantially lower than PICA $\left(0.96 \mathrm{~g} / \mathrm{cm}^{2}\right)$. Resolite-18 and CBCF have values similar to PICA, while Hoplon-22's areal density was greater $\left(1.04 \mathrm{~g} / \mathrm{cm}^{2}\right)$. Because the desired mass of PICA for each round of testing was different, the values of areal density for PICA are also different between the two rounds.

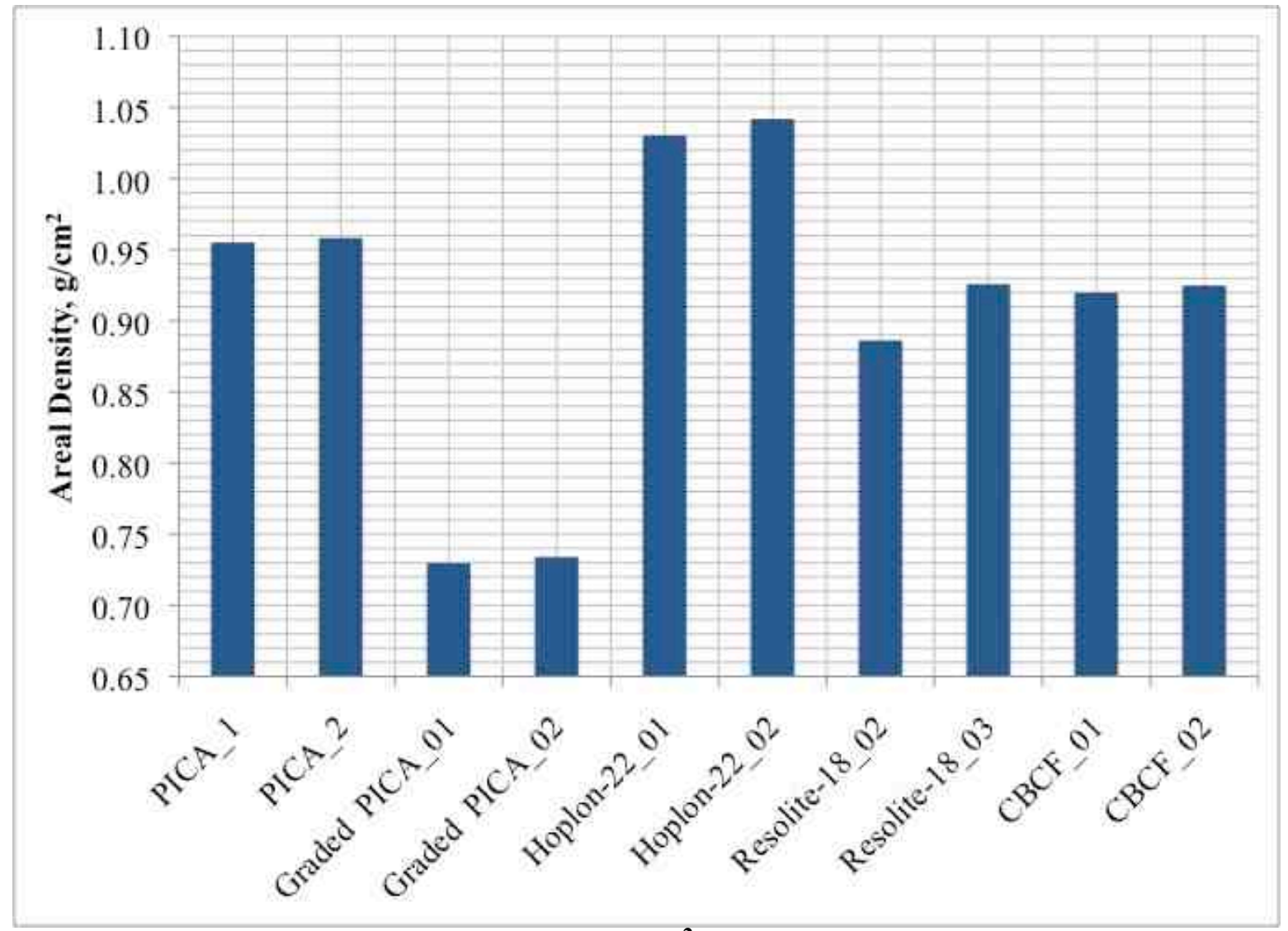

Figure 23. Areal Density $\left(\mathrm{grams} / \mathrm{cm}^{2}\right)$ for Round 2 virgin materials

\section{Mass loss}

Mass loss data are in Table 3. All models had a TC located at the bond line between the model and FRCI-12 insulator. Measurements were taken immediately before and after each test because atmospheric water absorption could allow model mass to vary. The results after the first laser exposure are shown in Figure 24 and results after the second laser exposure are shown in Figure 25.

As the testing baseline, PICA, when tested from its virgin state, had an average mass loss of 1.261 grams, and the charred PICA sample, when exposed to the second laser pulse, lost 0.102 grams.

For the first laser pulse exposure, FMI's CBCF and Graded PICA (model\# 02) had a smaller mass loss, and ARA's Hoplon-22 and Resolite-18 had greater (see Fig. 25). For the second laser exposure, charred CBCF had results similar to PICA, Graded PICA (model\# 01) had lower values, while both Resolite-18 and Hoplon-22 continued to show greater mass loss than PICA. 


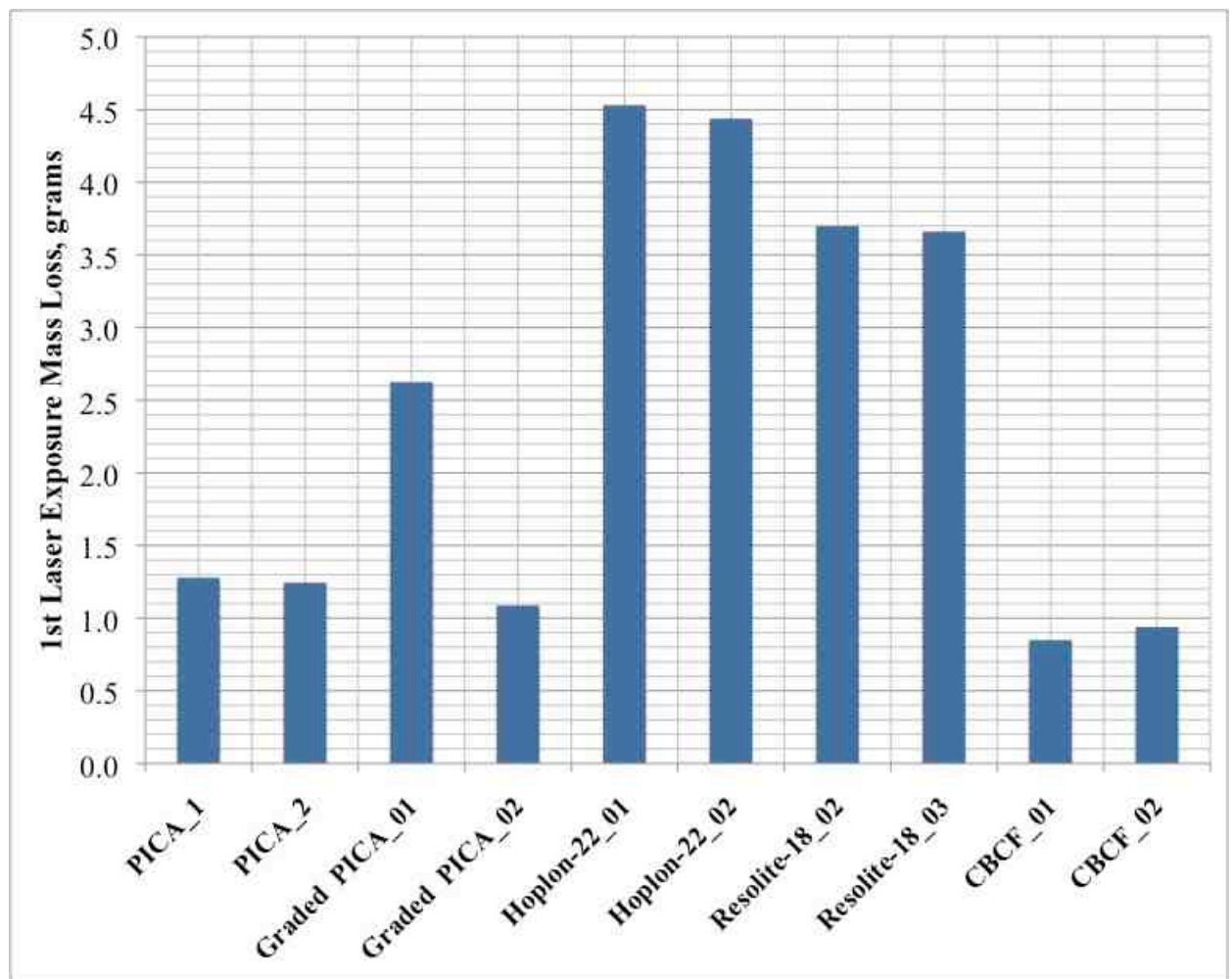

Figure 24. Mass loss from $1^{\text {st }}$ laser exposure of Round 2 materials

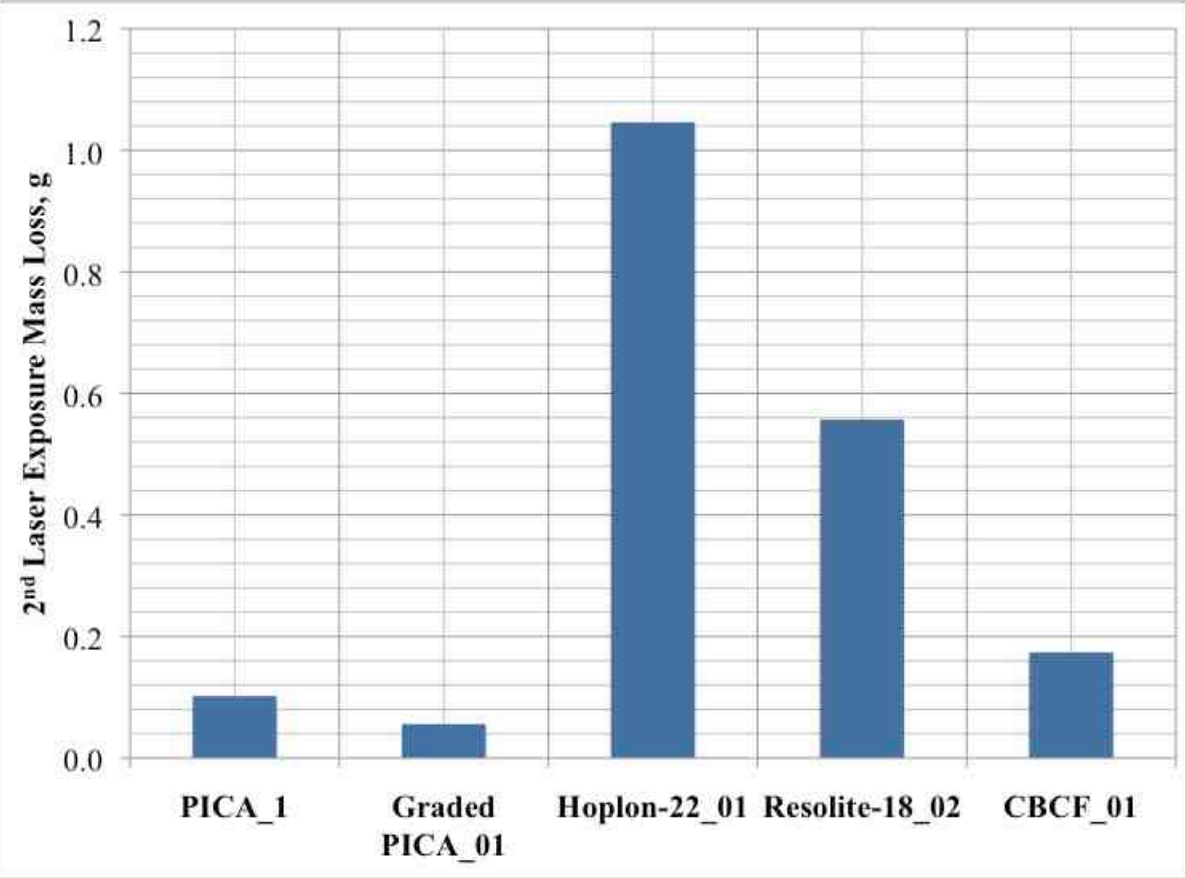

Figure 25. Mass loss after second laser exposure for Round 2 tested materials 


\section{Percentage virgin material remaining}

Using a sectioned sample, the percentage of virgin material remaining was found by measuring the distance from the bond line to the beginning pyrolysis edge, and then dividing this length by the original model thickness. Model thickness varied between materials because of the requirement that each material had an equivalent areal density. The results are given in Table 3 and shown in Figure 26.

As the benchmark material, PICA had values of $60.71 \%$ virgin material remaining after the first laser pulse and $60.57 \%$ after the second laser pulse. For this metric, only CBCF outperformed PICA, with values of $60.61 \%$ and $60.67 \%$ respectively. Hoplon- 22 had the lowest values of $35.39 \%$ and $27.78 \%$, respectively.

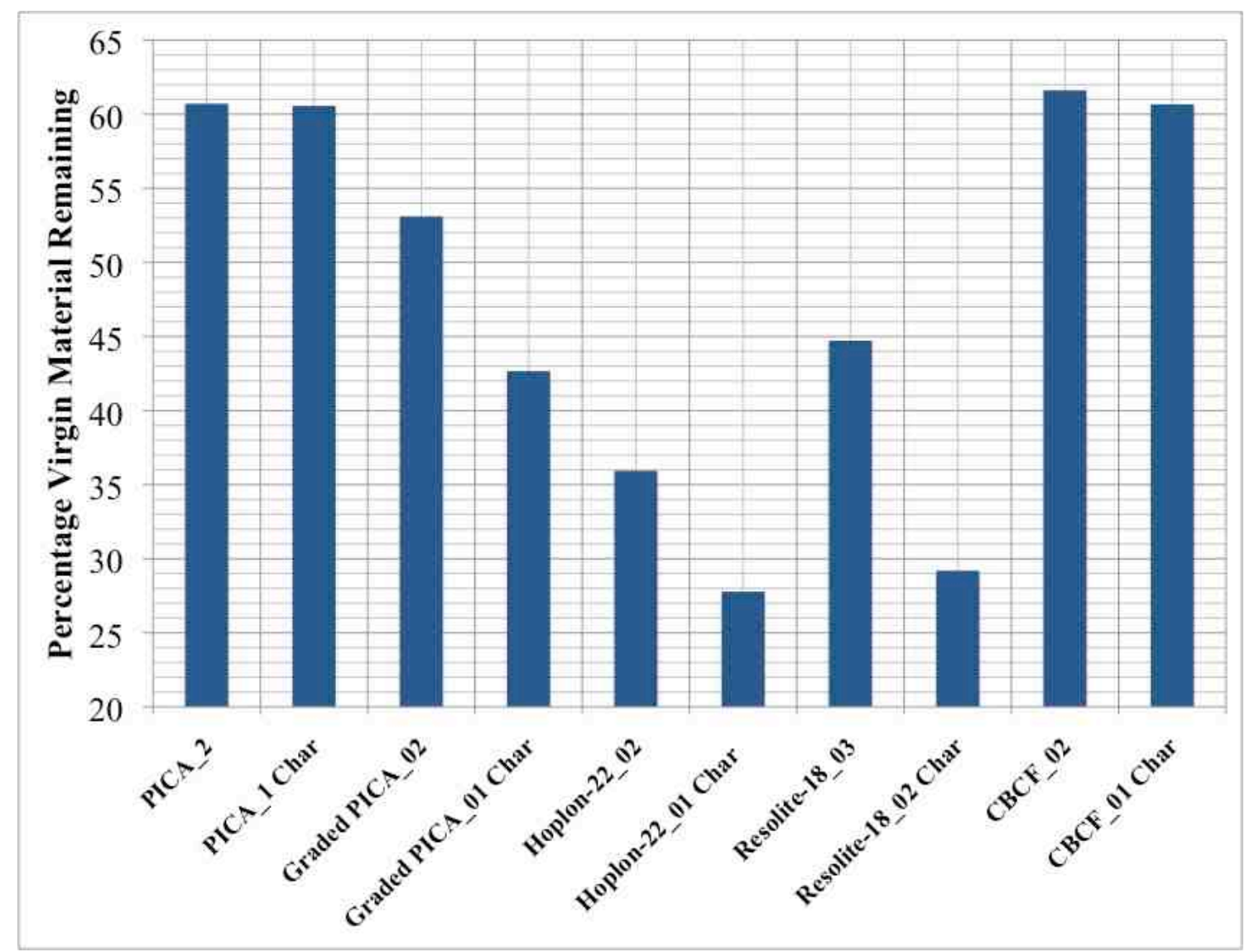

Figure 26. Percentage virgin material remaining for Round 2 tested materials

\section{Maximum bond line temperature}

Maximum bond line temperatures for all models tested are given in Table 3. Figure 27 shows a comparison of the maximum bond line $\mathrm{TC}$ temperatures recorded after the first laser pulse exposure, and Figure 28 shows a comparison of the maximum bond line TC temperatures recorded after the second laser exposure.

For the results from first laser exposure, the benchmark material, PICA, had a maximum bond line temperature of $93.2^{\circ} \mathrm{C}$. The only material to substantially outperform PICA for this metric was $\mathrm{CBCF}$, with a value of $64.7^{\circ} \mathrm{C}$. The material with the highest values was Graded PICA (model\# 01), with an exceptionally high value of $384^{\circ} \mathrm{C}$. This value is probably due to having the fiberform act to channel the pyrolysis gases to the thermocouple, thereby measuring the pyrolysis 
gas temperature. For the second Graded PICA model tested, the maximum bond line temperature was a more reasonable $150.1^{\circ} \mathrm{C}$. Based on the results shown in Fig. 27, Hoplon-22 and Resolite18 had very similar responses compared to virgin PICA.

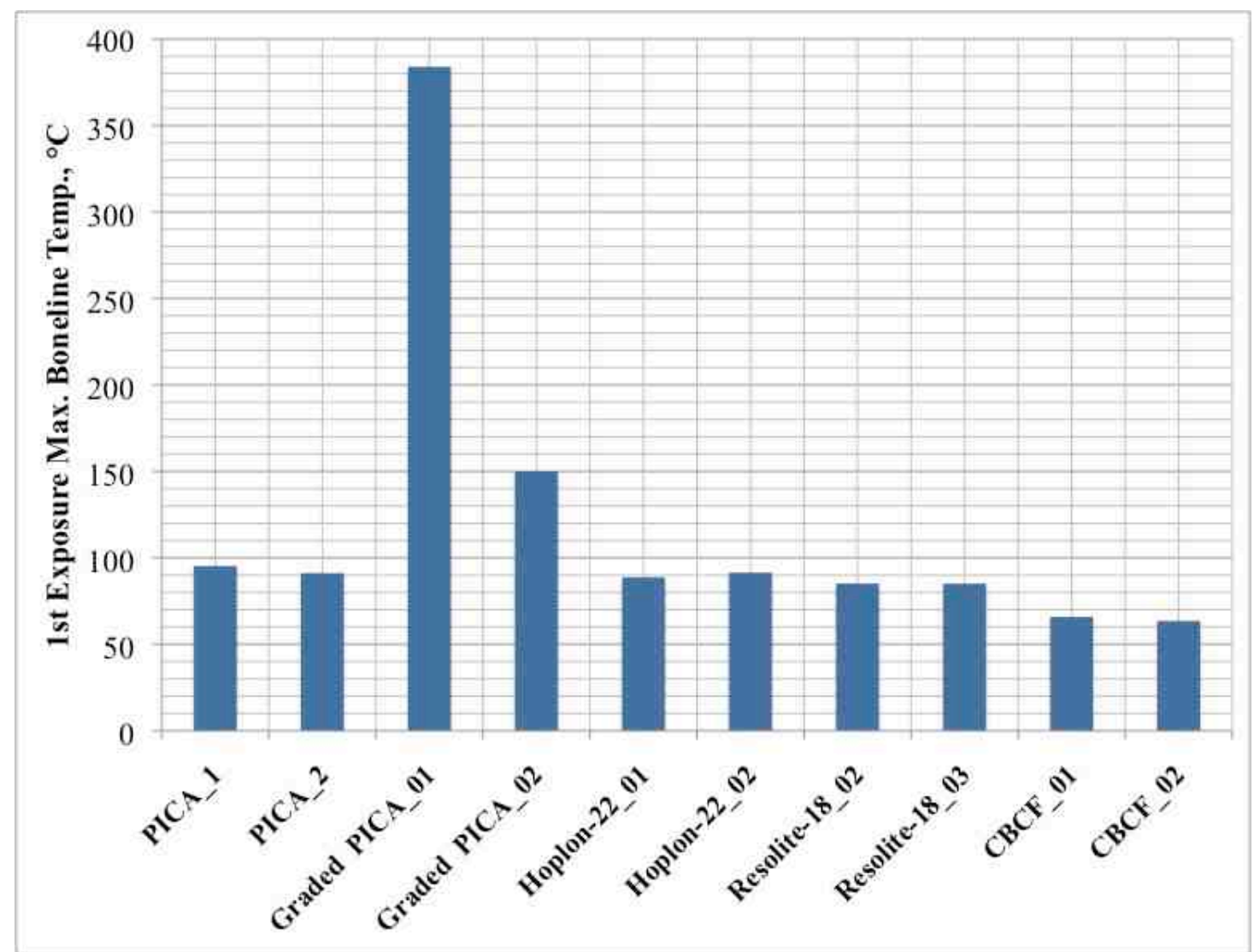

Figure 27. Maximum bond line temperature for Round 2 models after being exposed to the first laser pulse

The maximum bond line temperature results from the second laser pulse (representing vehicle entry) on the charred samples are shown in Figure 28 . Here, Graded PICA $\left(151^{\circ} \mathrm{C}\right)$ and Hoplon$22\left(191^{\circ} \mathrm{C}\right)$ had values much higher than PICA $\left(107^{\circ} \mathrm{C}\right)$, while Resolite- 18 was similar $\left(115^{\circ} \mathrm{C}\right)$ and $\mathrm{CBCF}$ was much lower $\left(59^{\circ} \mathrm{C}\right)$. These results are possibly related to mass loss, and a correlation seems to exist between the amount of mass lost from the first laser pulse relative to PICA (Fig. 25) and maximum bond line temperature from the second pulse. Generally speaking, if a material lost more mass than PICA in the first laser exposure, its bond line temperature would increase over that of PICA during the second laser exposure. 


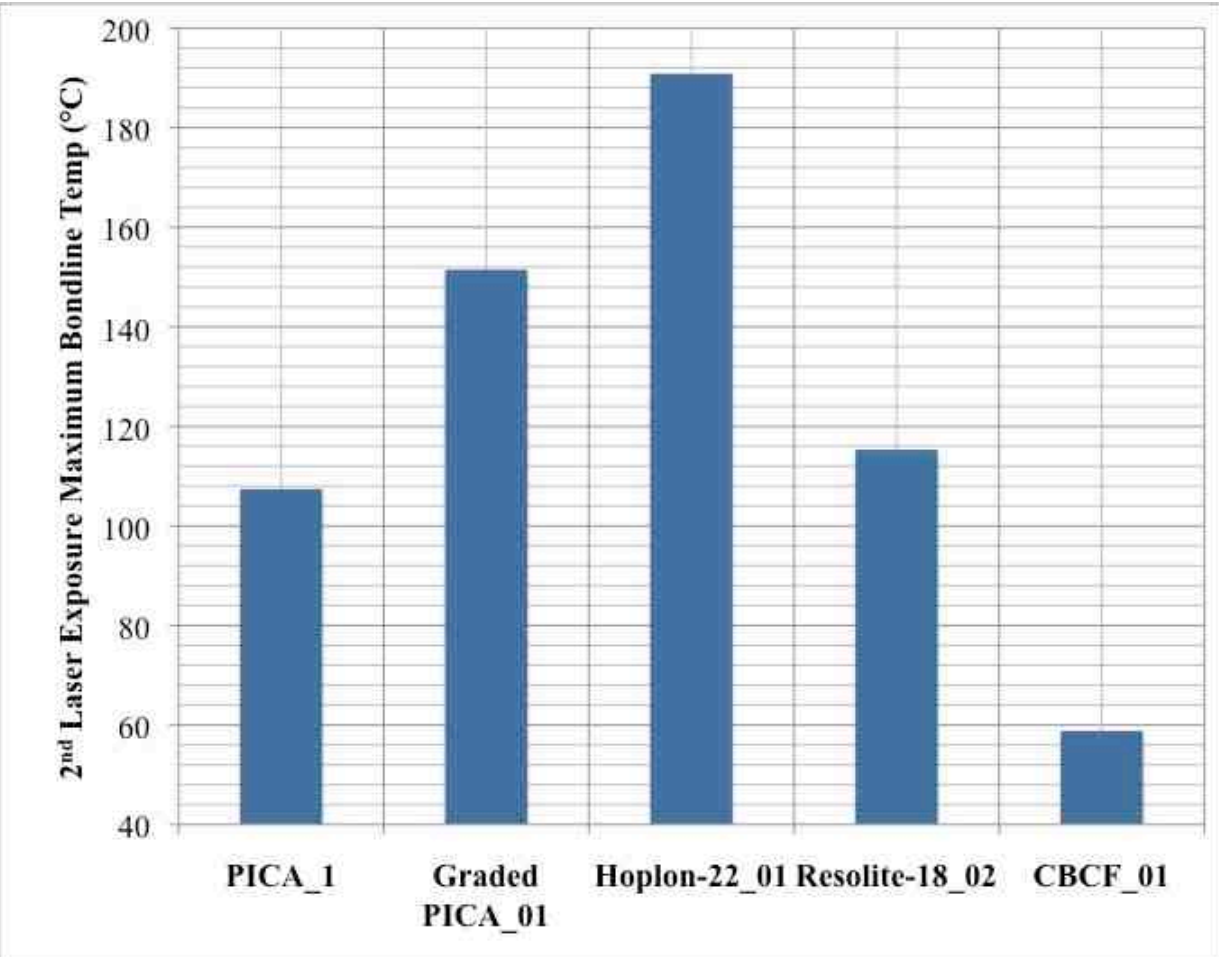

Figure 28. Maximum bond line temperature for Round 2 models after being exposed to the second laser pulse.

\section{Discussion of Round 2 Test Results}

Of all the materials tested, CBCF had the best performance when compared to PICA. It had a lower maximum bond line temperature for each laser exposure and similar values for percentage virgin material remaining, mass loss, and areal density.

Graded PICA had a much lower areal density than PICA. Of the two models tested, one (model\# 01) had substantially higher bond line temperatures and mass loss compared to PICA or the other Graded PICA model (model\# 02). It is unclear why this model had these results. Graded PICA model\# 02 had higher bondline temperatures for both laser pulses, lower percentage virgin material remaining, and similar mass loss when compared to PICA

Hoplon-22 had similar maximum bondline temperatures compared with PICA for the first laser pulse, but for the second laser pulse, its value was much greater. Hoplon-22 also had a greater char depth (lower percentage of virgin material remaining) and greater mass loss and areal density when compared to PICA.

Resolite-18 had similar maximum bond line temperatures for the first laser exposure compared to PICA, but much higher temperatures for the second laser pulse. It had greater mass loss and a lower percentage of virgin material remaining than PICA, but its areal density was similar to PICA. Some cracks are evident in the sectioned sample (see Fig. 21d).

Results from these tests were used as part of the down-selection process for determining which materials would move into the EDL TDP development phase and which materials would remain in the screening process. 


\section{Conclusions}

Novel materials have been developed and supplied for testing at Wright-Patterson Air Force Base's LHMEL testing facility as part of the NASA Entry, Descent, and Landing Project. The test objectives of exposing the materials to a $\mathrm{CO}_{2}$ laser pulse and recording bond line temperatures, mass loss, and char depth (as a percentage of virgin material remaining) for this work have been completed. Pre- and post-test photographs of the models have also been taken.

One of the goals of the program was to demonstrate the ability of new materials to be made of varying density through the material thickness. This capability may allow a heat shield designer to tailor the density of a material to take advantage of having a higher density for ablation and a lower density for an insulator. For Round 1 of testing, nearly all of the materials except PICA and PIRAS-22 had a "dual layer" design with different density ablators stacked atop one another. For Round 2 testing, Graded PICA was the only material of varying density.

Another goal of the project was to demonstrate the ability to place PICA-like materials and materials of varying density into honeycomb. Being able to pack a material in honeycomb has the advantage of being able to produce one type of monolithic heat shield. For the Round 1 tested materials, MonA and BPAFG were each packed in honeycomb.

For the test metric of char depth (given as a percentage material remaining), the Lockheed Martin CC/Calcarb tested in Round 1 outperformed PICA while the FMI CBCF tested in Round 2 showed results comparable to PICA.

Another test metric was maximum bond line temperature. ARA's P28/P15 and PIRAS-22 tested in Round 1 were both able to outperform PICA. However, two materials, Lockheed Martin's MonA and Boeing's BPAFG showed comparable peak bond line temperatures to PICA while being in honeycomb. Being in honeycomb is significant because the honeycomb was metallic and therefore had a high thermal conductivity. For materials tested in Round 2, FMI's CBCF consistently outperformed PICA, while ARA's Resolite-18 had results similar to PICA.

This work was part of the NASA EDL TDP TPS element for testing of candidate, vendorsupplied, rigid TPS materials. The results generated from this testing program will be used as part of the down-selection process to determine which materials will continue to the next stage of development and which materials will need to repeat the screening process. Material development activities in the next stage includes determining material properties, developing material response models, and performing arc-jet testing for material response.

\section{Acknowledgments}

The authors would like to acknowledge the support of the Exploration Technology Development and Demonstration (ETDD) Program, managed at NASA Glenn Research Center. The work documented in this paper was performed as part of ETDD Entry, Descent, and Landing (EDL) Technology Development Project, which is managed at NASA Langley Research Center and supported by NASA Ames Research Center, NASA Johnson Space Center, and the Jet Propulsion Laboratory.

The authors also gratefully acknowledge the support provided by the Thermal Protection Materials Branch and the Aerothermodynamics Branch of NASA Ames Research Center through NASA Contract No. NNA10DE12C with ERC Corporation. 


\section{References}

${ }^{1}$ Edquist, K.T., Dyakonov, A., Wright, M.J., and Tang, C.Y. "Aerothermodynamic Design of the Mars Science Laboratory Heatshield" AIAA paper 2009-4075, 41st AIAA Thermophysics Conference, June 2009, San Antonio, Texas.

${ }^{2}$ Hui, T., Johnson, C., Rasky, D., Hui, F., Hsu, M., Chen, Y-K., "Phenolic Impregnated Carbon Ablators (PICA) For Discovery Class Mission”, AIAA paper 1996-1911, presented at $31^{\text {st }}$ AIAA Thermophysics Conference, New Orleans, LA, June, 1996.

3 Henline, W.D., "Thermal Protection Analysis of Mars-Earth Return Vehicles," Journal of Spacecraft and Rockets, Vol. 29, No. 2, March-April 1992.

${ }^{4}$ Wright, M., Beck, R.., Slimko, E., Edquist, K., Driver, D., Sepka, S., Slimko, E., Willcockson, W., DeCaro, A., "Sizing and Margins Assessment of the Mars Science Laboratory Aeroshell Thermal Protection System", AIAA paper 2009-4231 41st AIAA Thermophysics Conference, June 2009, San Antonio, Texas.

${ }^{5}$ Kontinos, D., Stackpoole, M., "Post-Flight Analysis of the Stardust Sample Return Capsule Earth Entry,"AIAA 2008-1197, January 2008.

${ }^{6}$ Beck, R., Driver, D., Wright, M., Laub, B., Hwang, H., Sepka, S., Slimko, E., Edquist, K., Willcockson, W., Thames, T., "Development of the Mars Science Laboratory Heatshield Thermal Protection System", AIAA paper 2009-4229 41st AIAA Thermophysics Conference, June 2009, San Antonio, Texas.

${ }^{7}$ McGuire. M.K., "Dual Heat Pulse, Dual Layer Thermal Protection System Sizing Analysis and Trade Studies for Human Mars Entry Descent and Landing", AIAA paper 2011-343, presented at 49th AIAA Aerospace Sciences Meeting including the New Horizons Forum and Aerospace Exposition 4 - 7 January 2011, Orlando, Florida

${ }^{8}$ Arnold, J., Venkatapathy, E., Chen, Y-K.,Sepka, S., Argrwal, P., "Validation Testing of a New Dual Heat Pulse, Dual Layer Thermal Protection System Applicable to Human Mars Entry, Descent and Landing", AIAA paper 2010-5050, presented at 10th AIAA/ASME Joint Thermophysics and Heat Transfer Conference 28 June - 1 July 2010, Chicago, Illinois

${ }^{9}$ Laub, B., Venkatapathy, E., "Thermal Protection System Technology and Facility Needs for Demanding Future Planetary Missions", presented at the International Workshop on Planetary Probe Atmospheric Entry and Descent Trajectory Analysis and Science, Lisbon, Portugal, 6-9 October 2003

${ }^{10}$ Zell, P., Venkatapathy, E., Arnold, J., “The Block-Ablator-In-a-Honeycom Heat Shield Architecture Overview", presented at the International Planetary Probe Workshop 7, Barcelona, Spain 12-18, June 2010.

${ }^{11}$ Eric, J., "Laser Hardened Materials Evaluation Laboratory Performs Evaluation Of Advanced Materials For Aerospace Systems", ML-00-15, AFRL Technology Horizons, Volume 1, Number 4, page 10, Dec. 2000.

12 Chen, YK., Milos, F.S., "Ablation and Thermal Response Program for Spacecraft Heatshield Analysis," Journal of Spacecraft and Rockets, Volume 36, Number 3, May-June 1999

${ }^{13}$ Leiser, D.B., Goldstein, H. E., and Smith, M., "Fibrous Refractory Composite Insulation," U.S. Patent 4, 148, 962, 1978. 